Motu Working Paper 20-14

\title{
A Growing Problem: Exploring Livestock Farm Resilience to Droughts in Unit Record Data
}

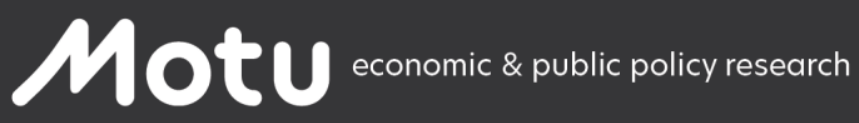

Levente Timar and Eyal Apatov

November 2020 


\section{Document information}

\section{Author contact details}

Levente Timar

Motu Economic and Public Policy Research

levente.timar@motu.org.nz

Eyal Apatov

Oranga Tamariki, Ministry for Children

eyal.apatov@ot.govt.nz

\section{Acknowledgements}

Funding for this study was provided by the Climate Change Impacts and Implications (CCII) research programme. We thank NIWA for the funding assistance and Statistics New Zealand for providing access to the Longitudinal Business Database. We also thank Suzi Kerr, Niven Winchester and audiences at Motu seminars for providing useful comments. Any errors that remain are, of course, the responsibility of the authors.

\section{Disclaimer}

The results in this paper are not official statistics, they have been created for research purposes from the Integrated Data Infrastructure (IDI) managed by Statistics New Zealand.

The opinions, findings, recommendations and conclusions expressed in this paper are those of the authors not Statistics NZ.

Access to the anonymised data used in this study was provided by Statistics NZ in accordance with security and confidentiality provisions of the Statistics Act 1975. Only people authorised by the Statistics Act 1975 are allowed to see data about a particular person, household, business or organisation and the results in this paper have been confidentialised to protect these groups from identification.

Careful consideration has been given to the privacy, security and confidentiality issues associated with using administrative and survey data in the IDI. Further detail can be found in the Privacy impact assessment for the Integrated Data Infrastructure available from www.stats.govt.nz.

The results are based in part on tax data supplied by Inland Revenue to Statistics NZ under the Tax Administration Act 1994. This tax data must be used only for statistical purposes, and no individual information may be published or disclosed in any other form, or provided to Inland Revenue for administrative or regulatory purposes.

Any person who has had access to the unit-record data has certified that they have been shown, have read, and have understood section 81 of the Tax Administration Act 1994, which relates to secrecy. Any discussion of data limitations or weaknesses is in the context of using the IDI for statistical purposes, and is not related to the data's ability to support Inland Revenue's core operational requirements. 
Motu Economic and Public Policy Research

PO Box 24390

info@motu.org.nz

+64 49394250

Wellington

www.motu.org.nz

New Zealand

C 2020 Motu Economic and Public Policy Research Trust and the authors. Short extracts, not exceeding two paragraphs, may be quoted provided clear attribution is given. Motu Working Papers are research materials circulated by their authors for purposes of information and discussion. They have not necessarily undergone formal peer review or editorial treatment. ISSN 1176-2667 (Print), ISSN 1177-9047 (Online). 


\section{Abstract}

Climate models indicate that New Zealand's farms will be increasingly exposed to adverse climate events in the future. In this study, we empirically investigate drought impacts on farm enterprises by linking financial, agricultural and productivity data from Statistics New Zealand's Longitudinal Business Database (LBD) with historical weather data from NIWA. Our sample consists of an unbalanced panel of over 67,000 observations of livestock farm enterprises between 2002 and 2012. We run a set of panel regressions with time and farm fixed effects to estimate the effect of changes in drought intensity on gross output, profit per hectare, current loans and intermediate expenditure of dairy and sheep-beef farms. To explore factors of resilience to droughts, we also examine how the estimates change with different farm characteristics. Most (but not all) of the estimated drought effects are significant, consistent across various specifications and of the expected sign. However, we have limited success in conclusively identifying farm characteristics that affect drought outcomes in our data.

JEL codes

Q12, C23

Keywords

Drought, farm enterprise, resilience, panel data, fixed effects 


\section{Table of Contents}

1 Introduction $\quad 1$

2 Droughts and farming $\quad 2$

$\begin{array}{llr}2.1 & \text { Measuring drought intensity } & 2\end{array}$

2.2 Drought impacts and responses 4

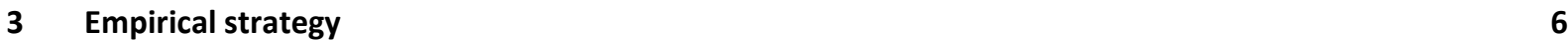

4 Data $\quad 7$

$\begin{array}{llc}4.1 & \text { Dependent variables } & 8\end{array}$

$\begin{array}{llr}4.2 & \text { Drought-related explanatory variables } & 9\end{array}$

$\begin{array}{lll}4.3 & \text { Other explanatory variables } & 12\end{array}$

$\begin{array}{llr}4.4 & \text { Sample construction } & 14\end{array}$

$\begin{array}{llr}4.5 & \text { Summary statistics } & 18\end{array}$

$5 \quad$ Discussion of estimation results $\quad 22$

$\begin{array}{llr}5.1 & \text { Dairy farming } & 23\end{array}$

$\begin{array}{ll}5.2 & \text { Sheep and beef farming }\end{array}$

6 Concluding thoughts $\quad 33$

$\begin{array}{lr}\text { References } & 37\end{array}$

$\begin{array}{lr}\text { Appendix } & 39\end{array}$

\section{Table of Figures}

Figure 1. Annual PED accumulation to end of June: average year (left) and 2008 (right) 3

Figure 2. Drought intensity (PED) over time by region 10

Figure 3. Drought extent (share of meshblocks in which drought intensity exceeds Q3) 11

Figure 4. Climate outlook (probability of low rainfall) by region 12

Figure 5. Number observations through time by industry 16

Figure 6. Number of observations by region and industry 17

Figure 7. Number of farms by the number of years observed 18

Figure 8. Mean gross output by sector $(\$ 1000) \quad 20$

Figure 9. Mean profit per hectare by sector (\$) 21

Figure 10. Mean current loans by sector (\$1000) 21

Figure 11. Mean intermediate expenditures by sector $(\$ 1000)$ 
Table 1. Summary statistics (pooled across all years)

Table 2. Estimation results for dairy

Table 3. Estimation results for sheep-beef 31

Table A1. Key sample restrictions and associated changes in sample size 
Dominated by pasture-based livestock farming systems, New Zealand's agriculture ultimately relies on rainfall to support production, making it highly susceptible to adverse climate events. In addition, the sector's prominent role in the economy is unusual among developed countries. The primary sector provides over half of New Zealand's total merchandise export earnings, while dairy farming alone contributes 3.5\% to GDP (NZIER, 2017).

Given the large share of the economy that depends on favourable climatic conditions, droughts in New Zealand can have significant and far-reaching impacts, particularly when compared to other developed countries (Kamber et al., 2013). The estimated cost of the 20122013 drought, the worst to hit New Zealand in 40 years, was around \$2 billion, reducing GDP by as much as $0.7 \%$ (OECD, 2016). As global climate changes, both the frequency and magnitude of extreme weather events is expected to rise, posing uncertainty for farmers dependent on consistent climatic conditions and potentially further increasing the exposure of the economy to such events. (OECD, 2016; Clark et al., 2011).

In this paper, we set out to investigate, firstly, the impact of droughts on farm-level economic outcomes and, secondly, determinants of farm resilience to droughts. New Zealand provides an ideal setting for exploring these questions for reasons other than the high salience of the subject. A rich data source allows us to relate weather outcomes and farm characteristics to economic outcomes at a unit-record level. Furthermore, farmers in New Zealand receive practically no financial support, including government assistance for adverse climate (or other) events, so farmer behaviour and estimated drought impacts are not distorted by policy.

Most research on the economic impacts of droughts focuses on outcomes at a macro scale, and even micro studies tend to be aggregated at the county level (Yusuke et al., 2019). Similar to Pourzand et al. (2020), we take advantage of the linking of farm production data from Agricultural Production Surveys and Censuses (APS/APC) to financial and employment data in Statistics New Zealand's Longitudinal Business Database (LBD), and consider outcomes at the level of individual farm enterprises. The administrative nature of the data yields not only farmlevel detail, but also wide coverage. We estimate a set of fixed effects panel regressions to relate annual changes in drought intensity to selected farm economic outcomes, and then we assess how the estimates change with various farm characteristics. By exploiting exogenous variation in weather outcomes, our model can, in theory, causatively identify the estimated economic impacts (Dell et al., 2014). 
In the next section we introduce potential evapotranspiration deficit, the variable we use to characterise drought intensity. We also explore the impacts of and potential responses to drought events among livestock farmers noting examples observed during past events. The relationships highlighted here will help formulate our estimations. In section 3 we describe our empirical model and in section 4 the data we use to implement it. Section 4 also documents the steps we have taken in constructing and cleaning the estimation sample, and it concludes with a presentation of summary statistics. In section 5, we discuss estimation results by livestock farming sector, and finally in section 6 we summarise our findings and offer concluding remarks.

\section{Droughts and farming}

In agriculture, droughts may be characterised based on various meteorological or hydrological criteria that are sometimes linked to the production impacts experienced-there is no universally accepted definition or metric. We use annual potential evapotranspiration deficit (PED) accumulation as our measure of drought intensity.

\subsection{Measuring drought intensity}

Evapotranspiration is the process whereby water held in the soil is gradually released to the atmosphere through a combination of direct evaporation and transpiration from plants. As the growing season advances, the amount a water lost from the soil through evapotranspiration typically exceeds rainfall, giving rise to an increase in soil moisture deficit. With the decrease in soil moisture, pasture production becomes moisture-constrained and evapotranspiration can no longer meet atmospheric demand. The difference between this demand, that is, potential evapotranspiration, and actual evapotranspiration is defined as Potential Evapotranspiration Deficit. As such, PED is determined by both soil moisture content and atmospheric moisture demand, and it is regarded as a robust measure of drought intensity and duration (Porteous \& Mullan, 2013).

In more intuitive terms, PED represents the amount of water in millimetres that needs to be replenished by either rainfall or irrigation to maintain plant growth unconstrained by soil water shortage (Porteous \& Mullan, 2013). When PED is high, plants do not have the full amount of water available they need for growth. As a rule of thumb, an accumulation of an additional 30 $\mathrm{mm}$ of PED is approximately equal to an extra week of reduced grass growth (Pearce et al., 2017). 
Despite the relative abundance of freshwater resources in New Zealand, droughts are fairly common in some parts of the country (Ministry of Agriculture and Forestry, 2009). East coast regions typically experience about $400 \mathrm{~mm}$ of PED accumulation each year, resulting in about 3 months of reduced pasture production. Figure 1 maps the annual accumulation of PED at a meshblock level over a 12-month period ending on 30 June for an average year and for 2008. ${ }^{1}$ The side-by-side comparison provides a contrast between a normal growing year and a prominent drought year. The 2007-2008 drought affected several agriculturally significant areas of the country, with Waikato, New Zealand's dominant dairy producing region, recording its driest January in a century. ${ }^{2}$ The maps also reflect the large variation in PED values geographically.

Figure 1. Annual PED accumulation to end of June: average year (left) and 2008 (right)

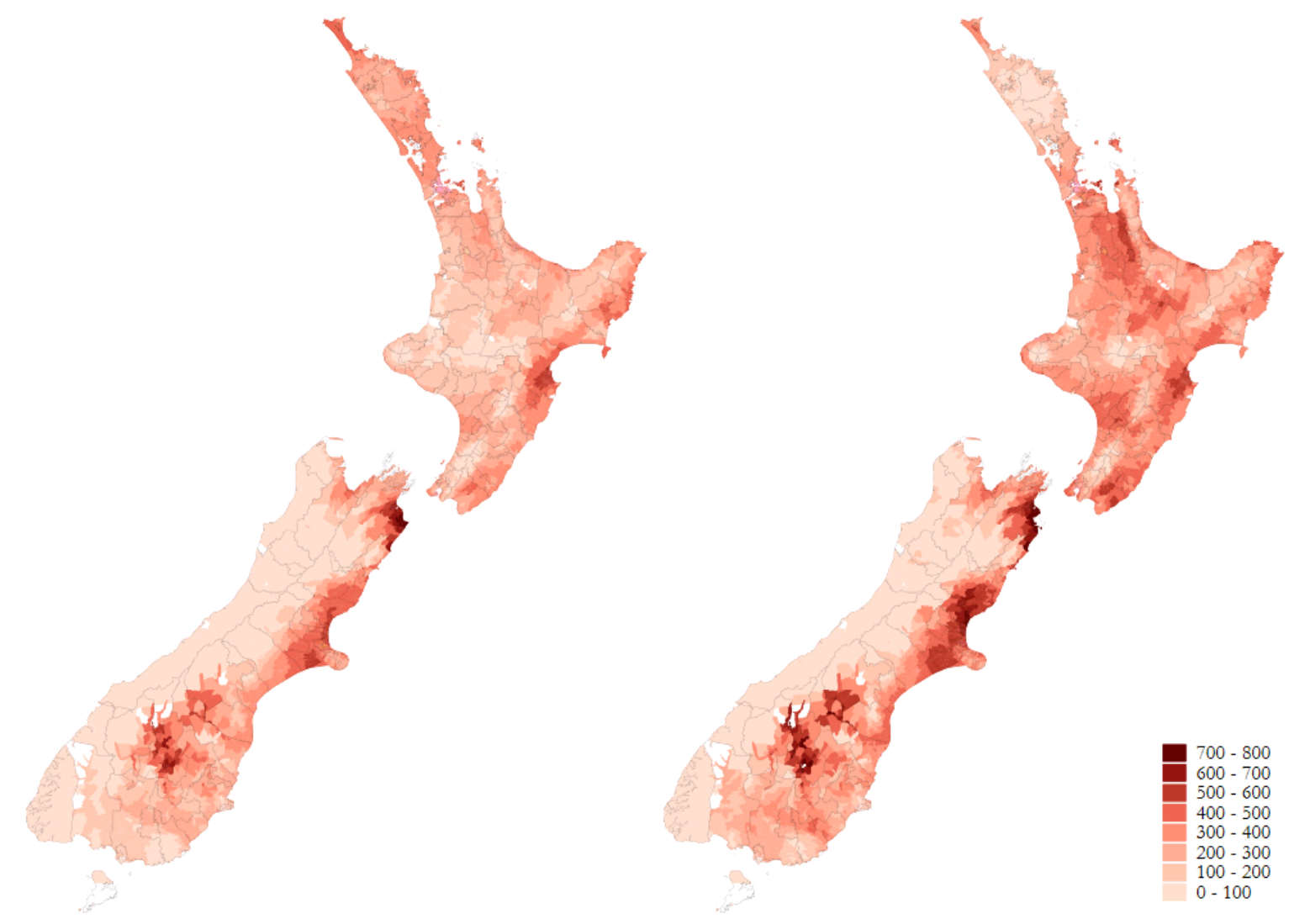

Notes: 12-month PED accumulation in millimetres is mapped at the meshblock level; Territorial Authority boundaries are super-imposed. The average map is based on the mean value of annual PED accumulation over the range of our climate data (2001-2014).

\footnotetext{
${ }^{1} \mathrm{~A}$ meshblock is the smallest geographic unit for which data is reported by Statistics New Zealand. In our empirical analysis, farm locations will be identified by meshblock.

2 For consistency with the notation we use in Figure 1 and elsewhere, we will henceforth identify droughts by their ending year. For example, from here on we will refer to the 2007-2008 drought simply as the 2008 drought.
} 
Future drought risk is expected to increase further in already drought-prone areas of New Zealand, with severe droughts occurring more often by mid- and late-century, and projections indicate increasingly severe drought conditions as greenhouse gas emissions increase (Clark et al., 2011; Ministry for the Environment, 2016; Ministry for the Environment \& Stats NZ, 2017).

\subsection{Drought impacts and responses}

Droughts are complex multi-dimensional phenomena, but the fundamental challenge they pose to livestock farmers in developed economies is the shortage of livestock feed that results from water-constrained plant growth (OECD, 2016). If left unmanaged, this shortage could lead to a loss of output and consequently a loss of profit. Farmers have at their disposal various drought management responses that aim to address the feed shortage itself or, at least, mitigate its consequences.

Farmers may devote additional resources to purchasing supplementary feed or relocating livestock to unaffected areas in an attempt to maintain production near normal levels. They may reduce the amount of feed their herd requires by destocking (selling off some livestock) thereby improving cash flow but at the same time sacrificing some future production. In some cases, they may have to reduce feed intake per livestock, but this results in declining production as well as potentially deteriorating livestock health and reproductive performance (which may lead to multi-year impacts on farm economics). As part of a drought response, farmers may also decide to contain expenses by forgoing or delaying spending on non-essential items.

The balance of trade-off between costs, output and profits associated with potential drought response strategies depends on a host of factors including the sector in which the farmer operates. In the remainder of this section, we spell out several of these factors and link them to farmer behaviour observed during previous drought events - we will, of course, also account for these factors (and some others) in our empirical estimation of drought impacts.

For dairy farmers, operational costs are generally harder to reduce than for sheep and beef farmers because reductions in spending on operational costs tend to be reflected in lost production and income more directly (Butcher Partners Ltd, 2009). In addition, most dairy farmers have reasonable ability to finance spending on drought responses due to the generally high profits and strong equity position that characterise the sector. For these reasons, dairy farmers tend to engage in costlier drought responses which aim to keep milk production relatively high.

For sheep and beef farmers, operational costs are easier to adjust. On average, they also have lower profits, lower equity and a correspondingly lower ability to borrow. Regardless of the 
use of supplementary feed, destocking is a common drought response among sheep and beef farmers as it makes it possible to cut back expenses while also providing some additional sales revenue during the event. However, destocking often takes place at sub-optimal stock weight, and it can also be costly and time-consuming to fully restock capital breeding stock down the line (Bevin, 2007).

Beside the intensity, timing (in relation to the growing year) and duration of a drought, all features that directly and clearly contribute to the severity of its impacts, the size of the drought-affected area also matters (Kamber et al., 2013). Geographically smaller droughts cause local shortages of feed meaning that affected farmers are more likely to be able to secure fodder from (or grazing rights in) unaffected areas nearby. In a large-scale drought the cost of these services increases not only due to greater transportation costs, but also because of greater demand for them (Burton \& Peoples, 2008). The 2008 drought, for example, lead to a sustained rise in the prices of hay, silage, and grain, with some prices undergoing a fourfold increase (Ministry of Agriculture and Forestry, 2009). Through its effects on market prices a large drought could thereby have repercussions also for farmers not directly experiencing drought conditions.

A drought event as well as a farmer's response to it may affect the farmer's ability to endure subsequent years of drought. Consecutive droughts could be particularly damaging if soil fertility, livestock numbers, livestock health or farm finances do not fully recover between the episodes (Peck \& Adams, 2010; Lawes \& Kingswell, 2012). When some regions of New Zealand were hit with back-to-back droughts in 2007-2009, meat processing increased in the first year as sheep and beef farmers culled capital livestock, but declined in the following year due to the smaller base of breeding livestock and lower reproductive rate (Butcher Partners Ltd, 2009). At the same time, experience with droughts can hone the skills needed to cope with future events, so farmers who have successfully recovered from a drought may in some cases be better placed to deal with the next one.

Correct expectations about weather can contribute to the success of drought responses. Decisions about strategies to follow often need to be made with imperfect information, before the event completely unfolds, as early action tends to be more effective. When making decisions about destocking, for instance, farmers must consider the prices they are able to get for their livestock - and prices tend to fall as the drought progresses both because of increased supply and because of poorer stock quality. While it is usually preferable to destock early, the severity of the drought is ex-ante uncertain and destocking is not easily reversible, so there is option value in delaying action. When farmers expect a drought event with more certainty, they are 
better placed to prepare appropriately and in a timely manner, whether by financial planning, pasture management, livestock management or by securing alternative feed sources.

Farm- and socio-economic factors like the farm's financial position, the strength of community support and international commodity prices could likewise affect a drought's impacts and farmers' ability to mitigate them. The 2008 drought, for instance, occurred at a time when milksolid prices were exceptionally high; dairy farmers' response was to spend heavily on supplementary feed to keep production as high as possible (Butcher Partners Ltd, 2009). (Nevertheless, milk production declined substantially.) During the same time, meat prices were comparatively low, and this allowed some sheep and beef farmers to take advantage of crosssectoral adaptation opportunities by selling feed to the dairy industry at a return even higher than that from their traditional livestock finishing (Butcher Partners Ltd, 2009).

\section{Empirical strategy}

We investigate the effect of droughts on farm financial outcomes and explore factors that affect the relative severity of drought impacts experienced across farms. To this end, we implement a flexible reduced-form estimation approach. The following-simplified-equation illustrates the basic structure of our model:

$$
Y_{i t}=\alpha+\beta D_{i t}+\gamma X_{i t}+\theta X_{i t} D_{i t}+\delta_{i}+\delta_{t}+\varepsilon_{i t}
$$

Here, $Y_{i t}$ denotes a financial outcome for farm $i$ at the end of period $t$. Outcome variables are associated with financial outcomes including production, expenses and profitability. Following from our use of tax data, time periods correspond to tax years. The financial outcome at the end of period $t$ is a function of drought intensity, $D_{i t}$, experienced by the farm during the period. ${ }^{3}$ Vector $X_{i t}$ denotes control variables that may modulate the response. In our application, these can be associated with the climate, geography, previous financial position and management of the farm. We include a complete set of farm fixed effects, $\delta_{i}$, in the estimation. These control for all time-invariant farm characteristics (both observed and unobserved in our data). We also include time fixed effects, $\delta_{t}$, to control for industry-wide shocks affecting all farms. Finally, $\varepsilon_{i t}$ is an error term capturing other exogenous shocks.

In this model, the parameters $\beta$ and $\theta$ both contribute to the marginal effect of drought intensity on the outcome variable. The coefficient of the interaction term, $\theta$, characterises how the drought impact changes for farms with certain attributes described by $X_{i t}$.

\footnotetext{
${ }^{3}$ Although not explicitly shown in the simplified equation above, our estimations will also account for the possibility of nonlinear and lagged drought impacts.
} 
Our empirical specifications use quadratic effects for drought intensity to capture potential non-linearities. In some specifications we introduce lagged drought intensity to allow for the possibility of longer-term impacts. We also include multiple control variables $(X \mathrm{~s})$ and, correspondingly, multiple interaction terms. Where possible, we implement log-log regressions, so the estimates represent percentage changes in the outcome variable in response to a one percent change in the explanatory variable. In all cases, we run separate regressions for dairy and sheep-beef farms. We estimate the model with a fixed effects estimator and robust standard errors using panel data. Identification is therefore based on deviations from the farmspecific mean. As noted above, this method controls for all time-invariant farm characteristics, including for geographic differences in baseline climate.

Drought intensity, a weather outcome, is credibly exogenous in our model. Combined with the use of panel data methods, this allows for a causal interpretation of its estimated impact on farm outcomes (Dell et al., 2014). Nonetheless, we point out that long-run impacts of climate change may be different form the contemporaneous impact estimated by the model for several reasons, including adaptation.

Finally, we note that compared to other countries, farmers in New Zealand have limited access to financial aid. The stated policy intention is that farmers should include all risks they face in their business operations and should not, in principle, rely on government for support. Accordingly, the New Zealand government does not intervene financially in agriculture following extreme weather events (OECD, 2016), so drought impacts and farmers' responses are not distorted by government policy.

\section{Data}

We source unit-record data on farm enterprises from Statistics New Zealand's Longitudinal Business Database (LBD). The LBD is a rich source of administrative and survey data for all economically significant businesses, including farm businesses, in New Zealand (Fabling \& Sanderson, 2016). Financial and productivity-related variables are taken from tax returns (IR10s) and Linked Employee-Employer data (LEED). These are collected at the permanent enterprise level (Fabling, 2011). Information about the location, age and industrial classification of firms comes from the Longitudinal Business Frame (LBF) (Seyb, 2003). Agricultural data are added from Agricultural Production Surveys and Censuses (Fabling \& Sanderson, 2016), and then aggregated to the permanent enterprise level to match the resolution of other variables, following the approach presented in Apatov et al. (2015). 
The location of enterprises is identified by meshblock, the smallest geographic unit for which data is reported by Statistics New Zealand. To ensure we can clearly assign data from the LBD to specific geographic locations, we will exclude from our sample all farm enterprises that operate in multiple meshblocks or whose location is, for some other reason, not clearly linked to a single meshblock. ${ }^{4}$ Focusing on farms with a distinct geographical location also helps in establishing a link between weather and farm outcomes.

We construct all of our variables so that they represent annual outcomes over the farm enterprise's tax year, taking into account its specific tax return filing month. ${ }^{5}$

\subsection{Dependent variables}

We assess the impact of drought intensity on four outcomes-gross output, net profit per hectare, current loans and intermediate expenditure-separately for dairy and sheep-beef farms. In combination, these outcomes are expected to elucidate key effects of and responses to droughts at the farm level. All variables are measured in real terms, deflated by either the consumer price index or the industry's producer price index, as appropriate.

We use gross output as a measure of production. It is calculated as income from production adjusted for changes in stock value. By adjusting for changes in stock value, we avoid potentially understating drought impacts during a destocking phase and overstating them during a restocking phase.

Net profit per hectare is calculated as net taxable profit divided by the productive land area of the farm. As net profit can be negative, the natural log of this variable is undefined for some observations. Although we implement log-log regressions for the other dependent variables, those for net profit per hectare are in a linear-log form, where the estimates represent dollar changes in net profit from proportional changes in the explanatory variables. ${ }^{6}$

Current loans are used to capture farms' short-term debt. They include cheque account liabilities, income tax account liabilities and overdrafts, but they exclude debt owed to on-bank creditors and any long-term debt (e.g., mortgages). We focus on current loans as we expect short-term debt to be more sensitive to weather shocks than long-term debt.

Finally, we include intermediate expenditure as a dependent variable. It is calculated as the sum of purchases and total expenses minus wages, bad debt, interest expenses and

\footnotetext{
${ }^{4}$ Section 4.4 and Table A1 in the appendix document our various sample restrictions and the associated changes in sample size.

${ }^{5}$ Depending on the farm enterprise, the tax year can end in March, May or June.

${ }^{6}$ The reason we consider profit per hectare rather than profit as an outcome is that dividing the variable by land area scales it for better comparability across farms of different sizes.
} 
depreciation. Intermediate expenditure includes ongoing costs such as those of animal feed and fertilizers.

\subsection{Drought-related explanatory variables}

We rely on annual PED accumulation from the National Institute of Water and Atmospheric

Research (NIWA) to measure drought intensity. ${ }^{7}$ Both technical and intuitive descriptions of PED were provided at the beginning of section 2 .

NIWA utilise daily data on rainfall and potential evapotranspiration to estimate PED (Porteous \& Mullan, 2013). The dataset we originally received contains monthly PED accumulation averaged at the meshblock level to match the spatial profile of our farm dataset. We aggregate this into annual accumulation for each farm enterprise based on its location while making an adjustment for the farm's tax return filing month. That is, for a farm with a tax year ending in June, the annual PED accumulation is calculated over 12 months starting in July of the previous year; for a farm with a tax year ending in March the accumulation starts in April of the previous year. ${ }^{8}$ The distribution of annual PED accumulation, henceforth simply referred to as drought intensity or PED, across regions and time in our sample is shown below in Figure 2.

\footnotetext{
${ }^{7}$ NIWA also publish an annual drought index which combines PED with other drought indicators, but at the time of writing this report it is not available for our entire study period.

${ }^{8}$ In practice, matching the calculation of PED accumulation to the firm's tax year in this way turns out to make little difference. Nearly the entire evapotranspiration deficit in a given year is accumulated over the summer and spring months, which greatly overlap for the three possible tax years (ending in March, May and June).
} 
Figure 2. Drought intensity (PED) over time by region
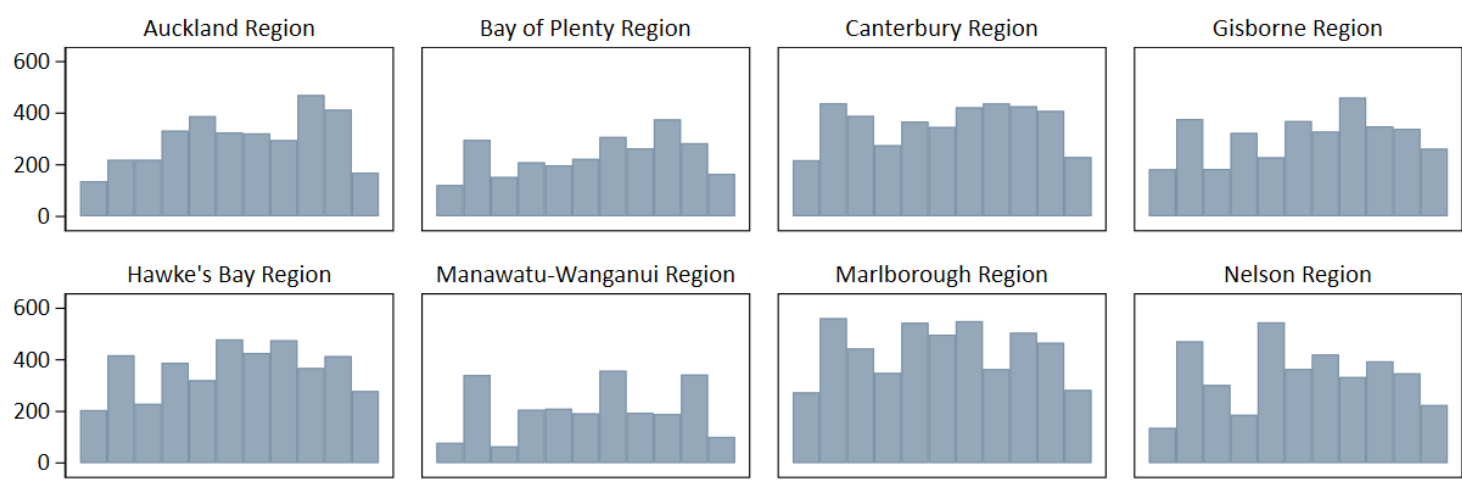

Manawatu-Wanganui Region
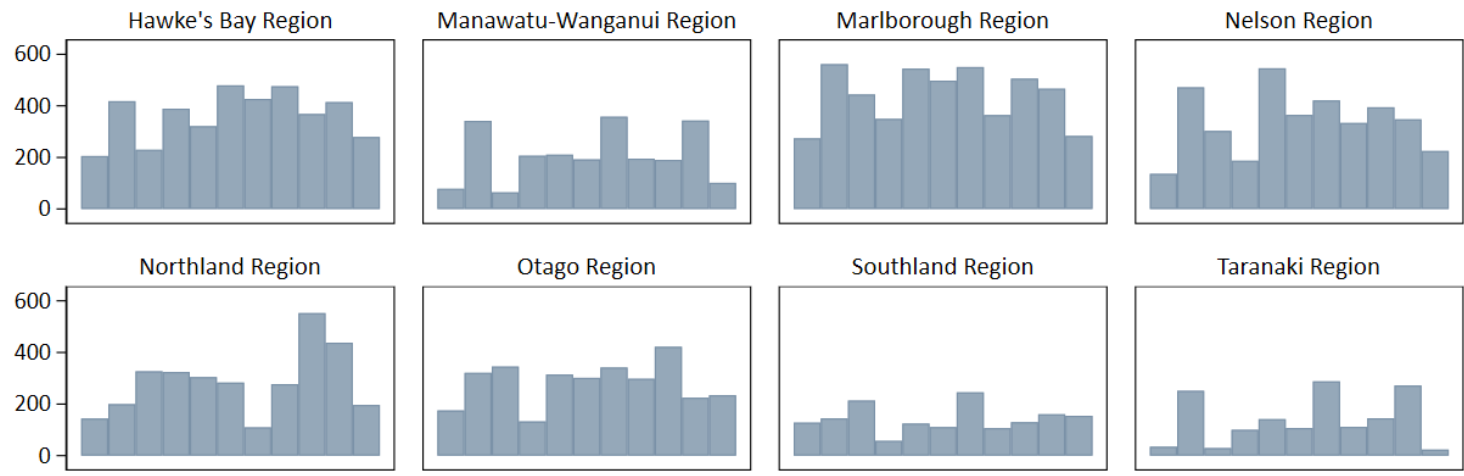

Otago Region

Southland Region
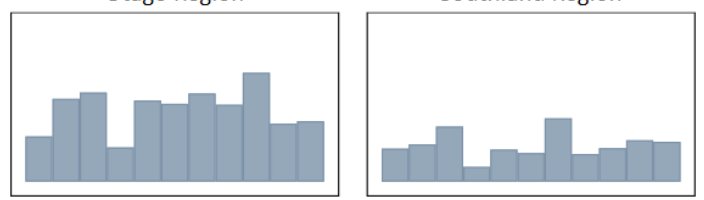

Taranaki Region
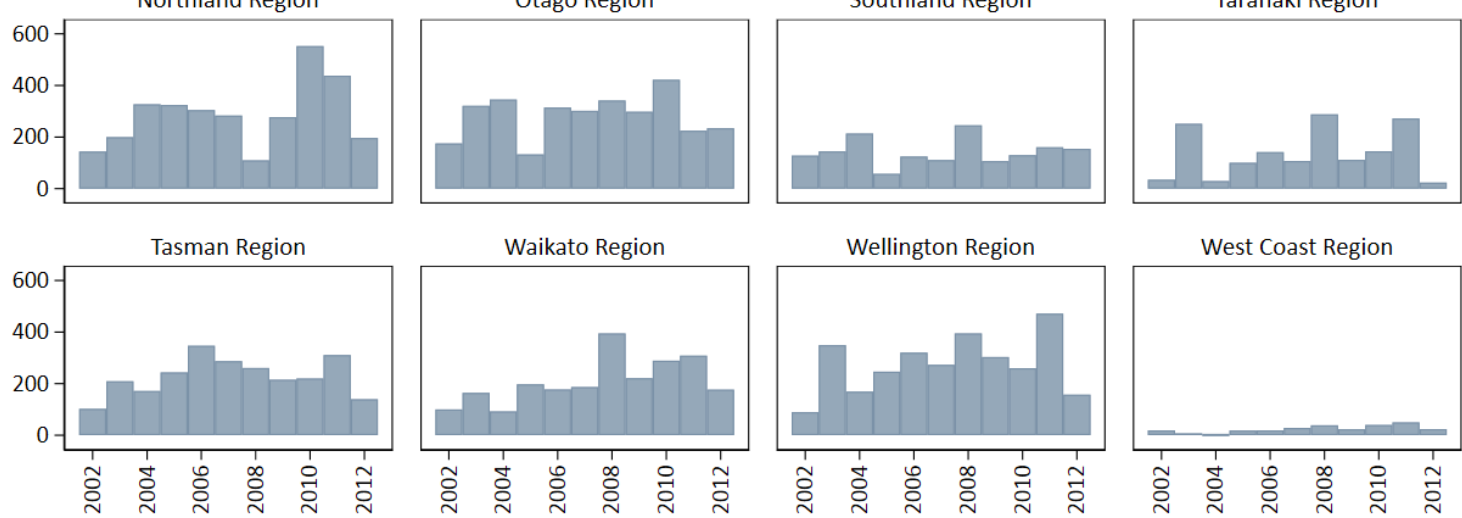

West Coast Region

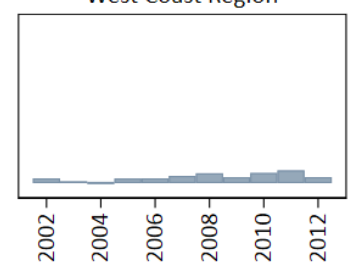

Our estimation sample includes several droughts that hit important farming regions of the country, including (but not limited to) droughts in Hawkes Bay (2007, 2008 and 2009), Waikato (2008), Taranaki (2008 and 2011), Manawatu (2008), Otago (2010) and Northland (2010 and 2011). However, it excludes the 2013 drought, one of the worst to hit New Zealand in recent history.

In addition to a quadratic effect for drought intensity, we introduce (in some specifications) other variables that help characterise past, current and expected future weather conditions. We include last year's PED to allow for the possibility of longer-lasting drought impacts. We also include drought extent, a variable indicating the spatial extent of drought conditions in a given year. We define this as the share of meshblocks in which PED in the given year exceeds the $75^{\text {th }}$ percentile (of PED values associated with that meshblock) over the range of our climate data, 2001-2014. ${ }^{9}$ Multi-regional or national drought events will be associated with a larger value of the drought extent variable than smaller local droughts; the distribution of this variable is shown in Figure 3.

\footnotetext{
${ }^{9}$ This is a slightly longer period than that of our estimation sample which is constrained by the availability of firm data. By taking the meshblock-specific percentile, we recognise in the construction of this variable that different levels of PED may qualify as drought conditions in different parts of the country.
} 
Figure 3. Drought extent (share of meshblocks in which drought intensity exceeds Q3)

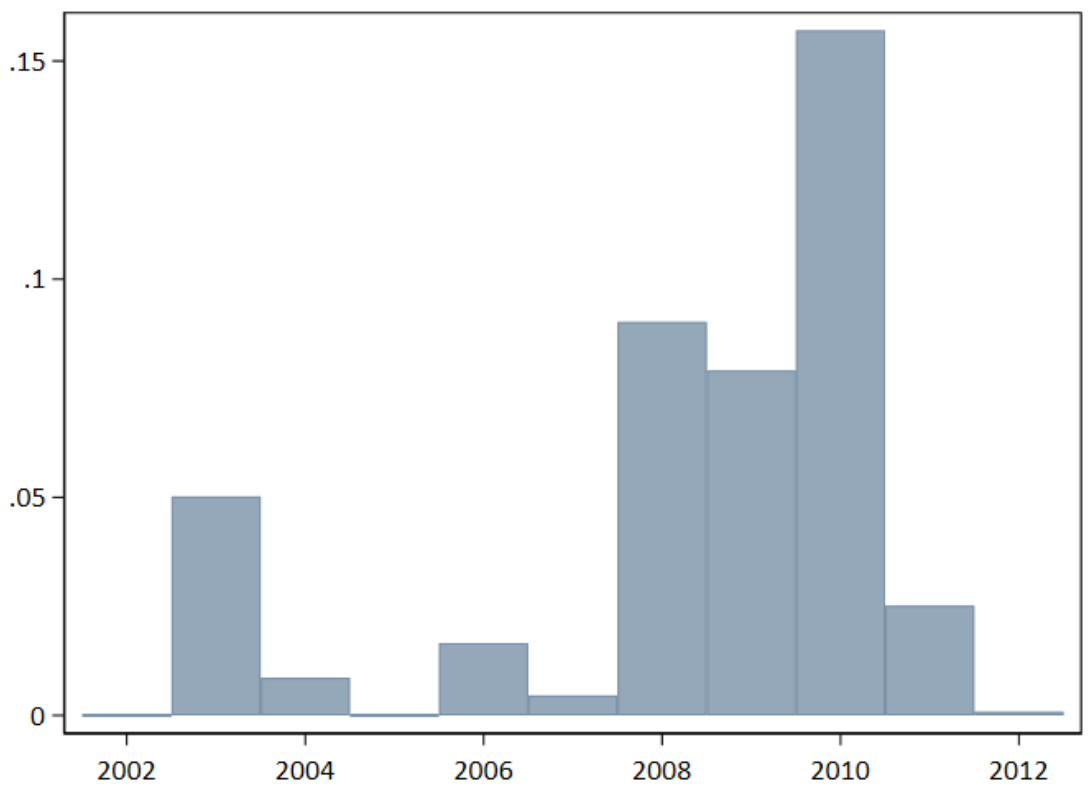

Lastly, to account for farmers' expectations regarding upcoming weather, we rely on Seasonal Climate Outlooks for rainfall released monthly by NIWA for broad climate regions (which may combine multiple Regional Council areas). The outlooks include probabilities for below-average rainfall over the upcoming 3-month period. We take the average probability for outlooks of the spring and summer months. High values are therefore associated with a high predicted probability of low rainfall conditions for the broad region. Note in Figure 4 that some regions have identical outlooks because they belong to the same broad climate region. 
Figure 4. Climate outlook (probability of low rainfall) by region
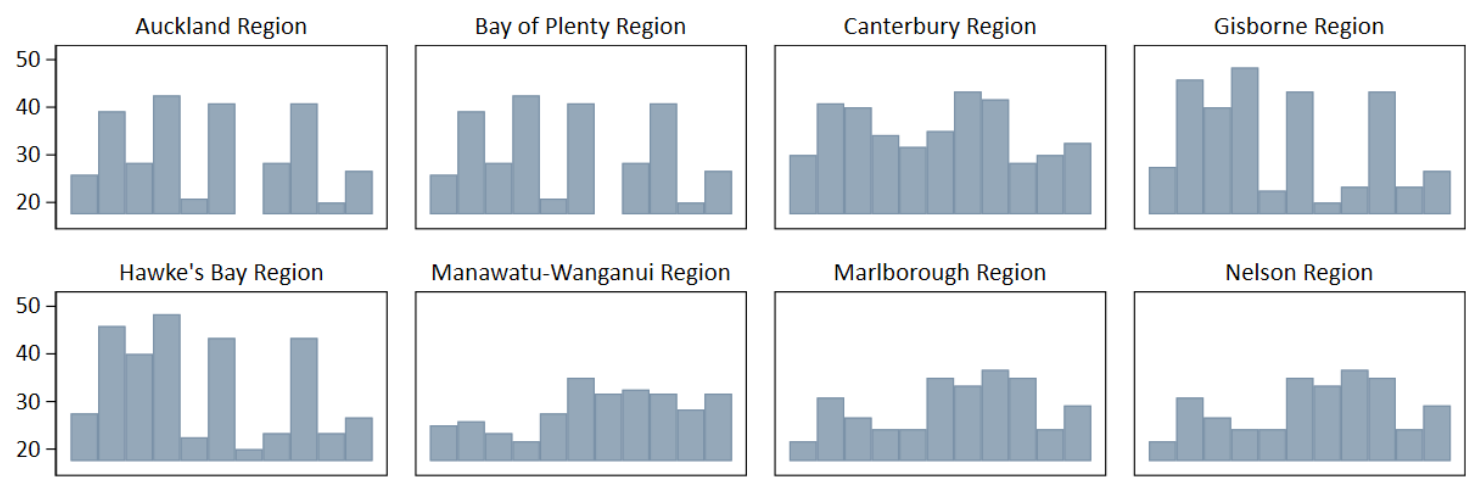

Manawatu-Wanganui Region
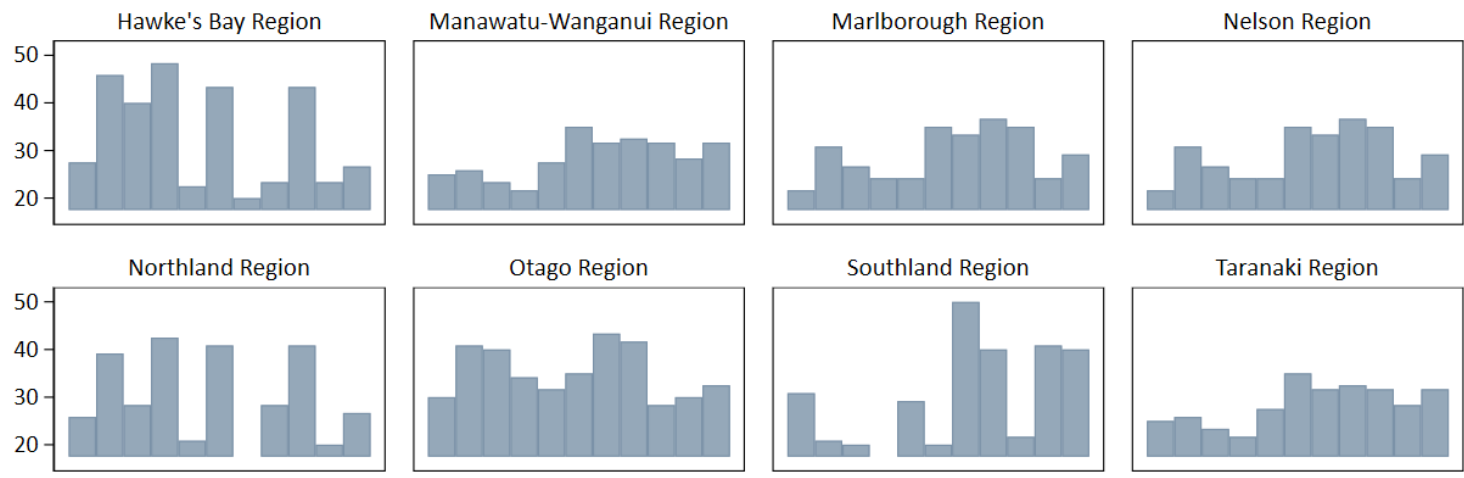

Otago Region

Southland Region

Taranaki Region
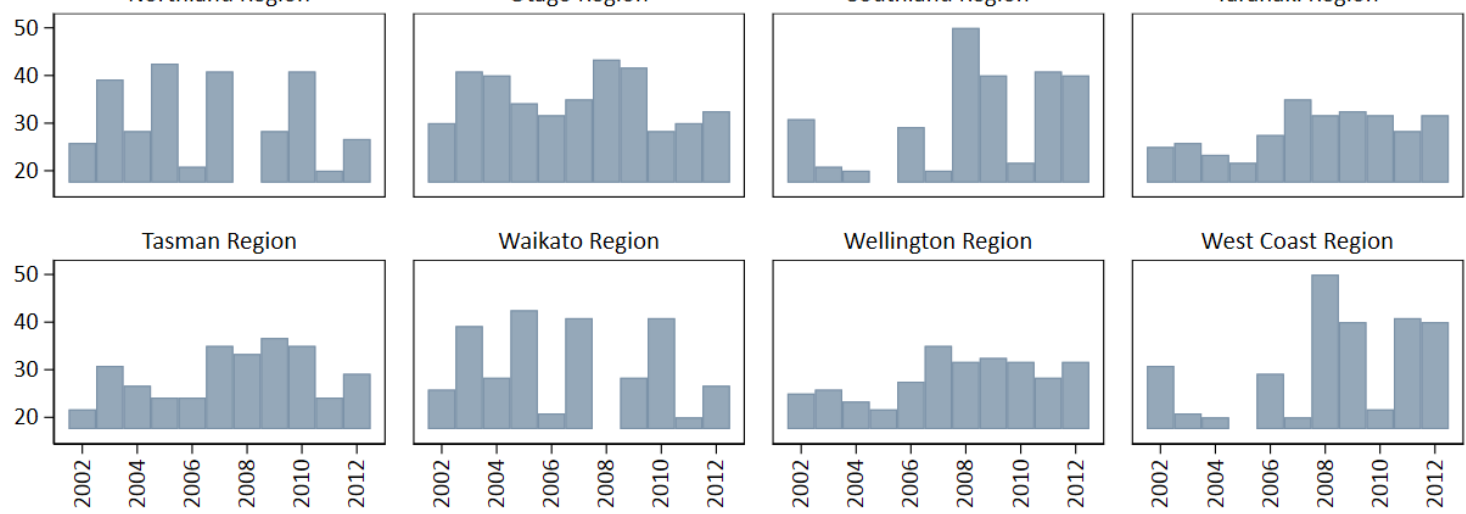

Although the spatial resolution of the climate outlooks is low, and below-average rainfall may have different implications in different regions, it is not unreasonable to expect that farmers would nonetheless make use of this information by combining it with their own experience and knowledge of their physical environment.

\subsection{Other explanatory variables}

The remaining independent variables fit into three broad categories: those associated with geography, the farm's previous financial status and farm management. Interaction terms between drought intensity and these variables are used to characterise drought impacts for farms with various attributes.

Before introducing these variables, it is worth noting that we exclude from the estimations direct production function inputs such as labour and capital. Including these variables as controls would lead to partially eliminating the explanatory power of drought intensity because they can be expected to be functions of drought intensity themselves. A farmer's response to a drought event might, for instance, include an adjustment of labour input. We would like to attribute the resulting change in output to the drought rather than to the change in labour as the drought is clearly the underlying cause (drought intensity is credibly exogenous in our model). By excluding 
production inputs such as labour we avoid over-controlling and ensure that the estimates reflect the full effect of the drought, including effects that feed through changes in inputs into production.

\section{Geography}

Four explanatory variables relate to features of the geophysical environment and geographic location of the farm. We use data on soil particle size and slope from the Land Environments New Zealand (LENZ) database (Leathwick et al. 2002). Particle size could contribute to drought outcomes as it can affect soil permeability and moisture storage capacity. Slope can likewise affect the ability of soils to retain water, and it may also be useful for differentiating between intensive and extensive (hill country) sheep-beef farms. As farm location is identified by meshblock, we include in our analysis the share of each farm's meshblock that is fine textured soil (silt or clay), and the mean slope within the meshblock. ${ }^{10}$

Ability to cope with droughts and other extreme events may also be affected by proximity to markets and various economic amenities offered by population centres. We include distance to nearest city in kilometres as one of our controls. Distance is calculated by taking a straight line from the meshblock centroid to the nearest highway, and then travelling along the highway to the city centroid. Finally, as a measure of the relative significance of dairying, we include the gross output share of the dairy sector in the farm's territorial authority. ${ }^{11}$ This variable is used to capture infrastructure and network effects and may also be associated with cross-sectoral adaptation opportunities.

\section{Finance}

Using IR10 data, we create three indicators to describe aspects of farms' financial position at the end of the previous tax year, our hypothesis being that farms in better financial position are better able to cope with droughts. The indicator variables identify farms that had an outstanding loan in the previous year, farms that made a net loss in the previous year and farms that had negative equity (liabilities exceeding assets) in the previous year. The summary statistics in section 4.5 show that loans and losses are fairly common among our sample of farms, but only a small proportion had liabilities greater than assets.

\footnotetext{
10 Some variables, including those measuring meshblock shares, can be zero. For mathematical convenience in taking the natural log of these variables, we add a small positive number, $\eta$, to all observations of these variables. We select $\eta$ such that it is by orders of magnitude smaller than the minimum observed non-zero value of each of those variables. The operation therefore has no perceptible effect on the distribution of the affected variables.

${ }^{11}$ A territorial authority is a tier of local government in New Zealand. Territorial authorities are smaller than regions but larger than meshblocks. The variable is calculated as total gross output of dairy farms divided by total gross output of dairy and sheep-beef farms in our sample. To minimize the effect of year-to-year fluctuations due to weather outcomes and price expectations, the numerator and denominator are sums over the entire sample period.
} 


\section{Management}

Four variables associated with farm management are acquired from the APS. These variables could be influenced by farm management decisions. Conceivably, farmers might even adjust them in responding to drought events, so adding them to the regression may lead to an over-controlling issue similar to what was discussed at the beginning of this section.

Nonetheless, they capture important aspects of farm heterogeneity in our context, so we include these variables in one of the model specifications (for each outcome variable).

First, we include the productive land area of the farm. This includes all grassland, tussock and danthonia for grazing, as well as grain, seed and fodder crop areas. While the farm fixed effects provide a way of controlling for the average size of each farm, they do not account for potential changes in grazed area, either as a result of on-farm management decisions or purchases and sales of land, from year to year. Crucially for our purposes, including land area may also provide a way to estimate a differential drought impact by farm size.

Based on responses to the APS, we also create a variable to indicate the estimated share of productive land area that is potentially irrigated. The quality of this variable is affected by the irregularity and inconsistency of relevant questions in production surveys and censuses. In only five of the eleven years of our sample was a question about irrigation posed. In some years the question refers to potentially irrigated land, in other years actually irrigated land was also elicited. Since 2005, no surveys have asked about irrigation, so data was collected in census years only. In constructing our variable, we therefore interpolate to years with missing data by assuming that, unless evidence to the contrary exists, potentially irrigated land area does not change from the previous response. This is then divided by the area of the farm's productive land to estimate the share that is potentially irrigated.

Finally, we calculate fertiliser (total lime and non-lime) intensity and effluent intensity as tons applied per hectare of productive land. These variables are intended to proxy for land-use intensity. Fertiliser intensity, in particular, may enable identification of differential drought effects in the highly heterogeneous sheep-beef sector. On the other hand, effluent is almost exclusively applied in dairying.

\subsection{Sample construction}

We build on the approach taken by Apatov et al. (2015) in constructing the sample. We consider enterprises classified as dairy or sheep-beef in both the LBD and the APS between 2002 and 
2012. As a starting point, we select the 94,401 observations that are for firms returning valid IR10 and valid APS forms in a given year. ${ }^{12}$

We then use information from the APS and other sources to implement sample restrictions designed to ensure that all observations relate to operating farms that are active predominately in the industry of interest. Table A1 in the appendix documents the effect of the various restrictions (discussed below) on sample size. Before splitting the sample into the two sectors, we require that firms have some productive land, we require the majority of livestock on the farm (by head count) to be cattle or sheep and we require that a larger land area is devoted to dairy or sheep-beef pasture than to forestry. We classify farms as dairy if most of the dairy stock on the land is owned by the farm and at least 80 percent of the stock units on the farm are dairy cattle. Similarly, we classify them as sheep-beef if at least 80 percent of stock units on the farm are sheep and beef stock. We keep only observations successfully matched with all productivity, financial and weather data.

The geographic location of farm enterprises is identified by meshblock in the LBF. For transparency and better match to weather and geographical data, we drop from our sample all farms whose location is not clearly identifiable. We select only firms that operate, at any given time, in a single meshblock within a single Regional Council area. In addition, we discard any observations of a farm enterprise where the data indicate a change in the region of location of the firm. ${ }^{13}$ We also exclude farm enterprises in their first year of operation and any observations with large outliers in the outcome variables. ${ }^{14}$

After applying these restrictions, our full estimation sample includes 17,046 observations of dairy farms, and 50,199 observations of sheep-beef farms, scattered across over 9,200 meshblocks. The distribution of these observations through time and space is illustrated in the next two figures. Depending on data availability for certain variables, some of our model specifications may include fewer observations.

\footnotetext{
${ }^{12}$ At this stage, we exclude observations for years in which the firm failed an IR10 quality check by Statistics New Zealand. We also exclude firms that appear in multiple agricultural industries or in non-agricultural industries, imputed firms and firms without relevant employment in the firm's geographic location.

13 However, we keep farms whose meshblock changes over time (within the same region). This affects between 6 and 7 percent of all observations in our sample. We are unable to establish what proportion of these represent genuine changes in location, administrative changes or data errors.

${ }^{14}$ Specifically, we remove observations larger than twice the $99^{\text {th }}$ percentile and smaller than half of the first percentile (or twice the first percentile for negative values).
} 
Figure 5. Number observations through time by industry

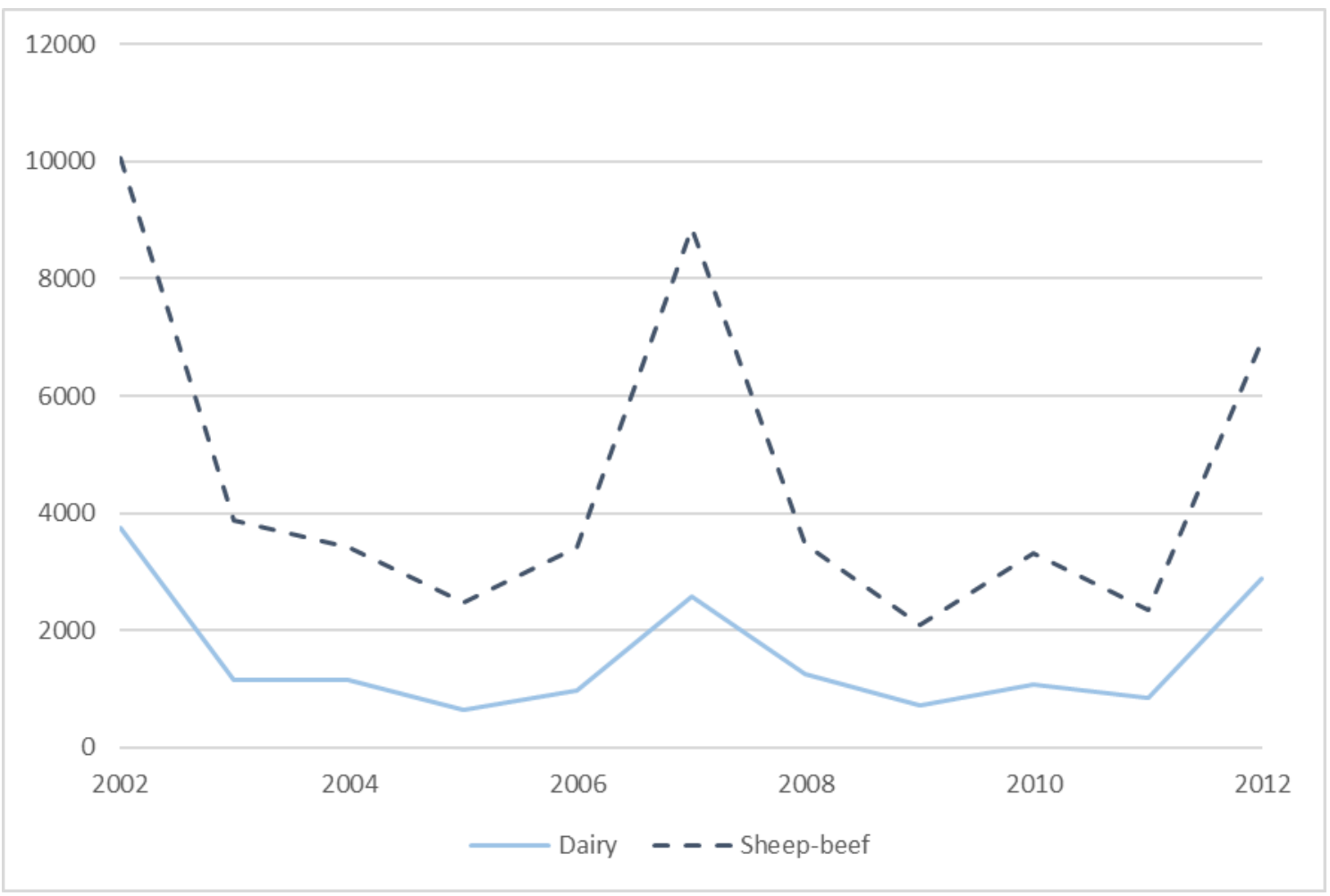

The peaks in Figure 5 clearly identify the years of the three Agricultural Production Censuses in our sample: 2002, 2007 and 2012. In the remaining years, only production surveys with a smaller coverage were administered. Overall, the figure indicates a reduction in the number of both sheep-beef and dairy firms over the decade. This reduction is not an idiosyncrasy of our sample, it is also confirmed by other data. According to Business Demography Statistics, the number of sheep-beef enterprises, as identified by the Australian and New Zealand Standard Industrial Classification (ANZSIC), fell by about 1.4\% per annum between 2002 and 2012. The number of dairy enterprises fell by about $2.1 \%$ per annum over the same period (Statistics New Zealand, 2014). At the same time, the average farm size has increased. 
Figure 6. Number of observations by region and industry

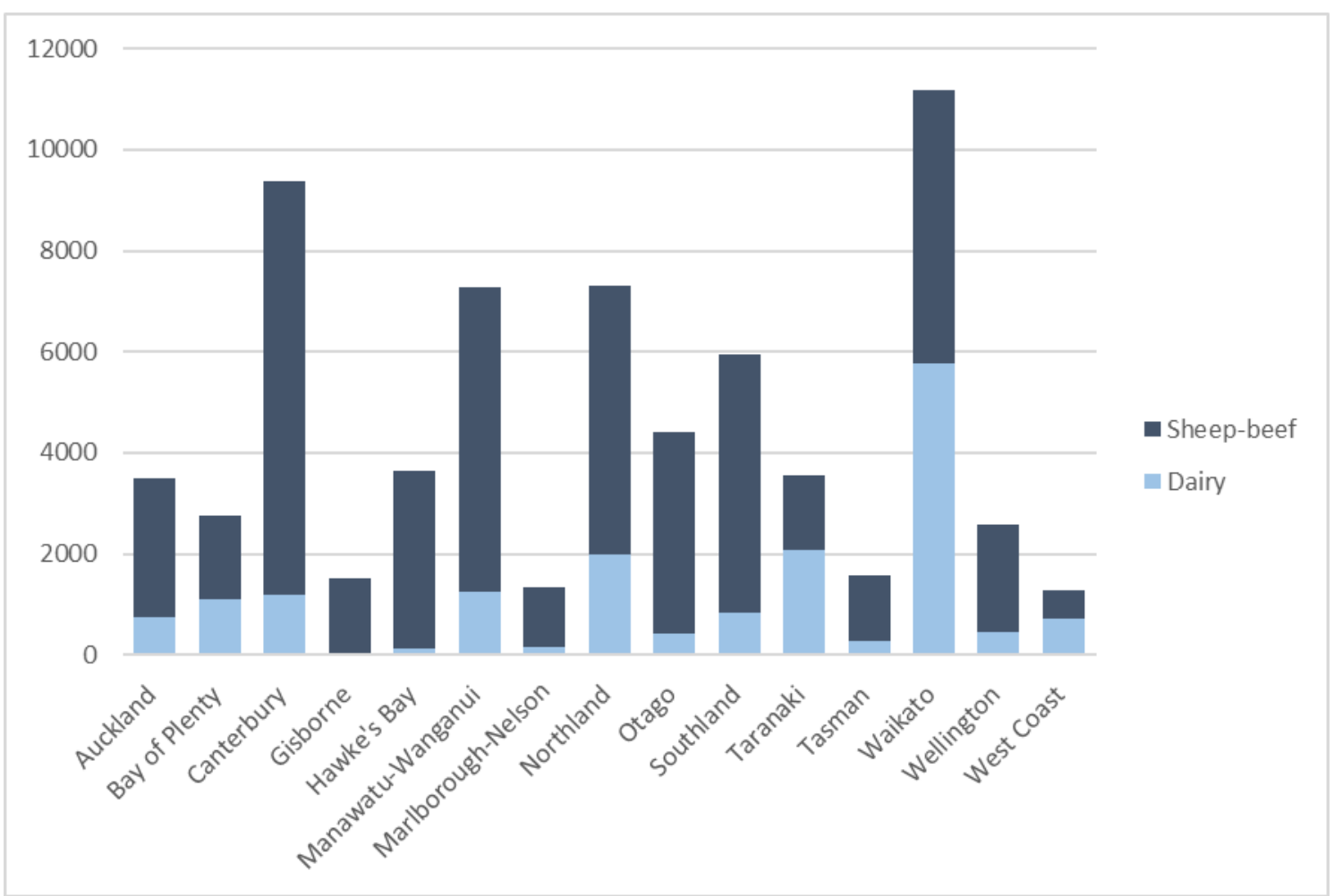

Note: Marlborough and Nelson regions have been combined in the figure to protect small counts in the Nelson region.

Observations of dairy farms come predominantly from the North Island: the Waikato Region alone contains as much as a third of them. The next three largest dairy regions (in terms of number of observations) are Taranaki, Northland and Manawatu-Wanganui-also all North Island regions. Canterbury, the largest dairy region in the South Island contains only about $7 \%$ of all dairy observations. Observations of sheep and beef farms are spatially more evenly distributed. Canterbury, Manawatu-Wanganui, Waikato, Northland and Southland each make up between 10 and $17 \%$ of the sheep-beef sample. 
Figure 7. Number of farms by the number of years observed

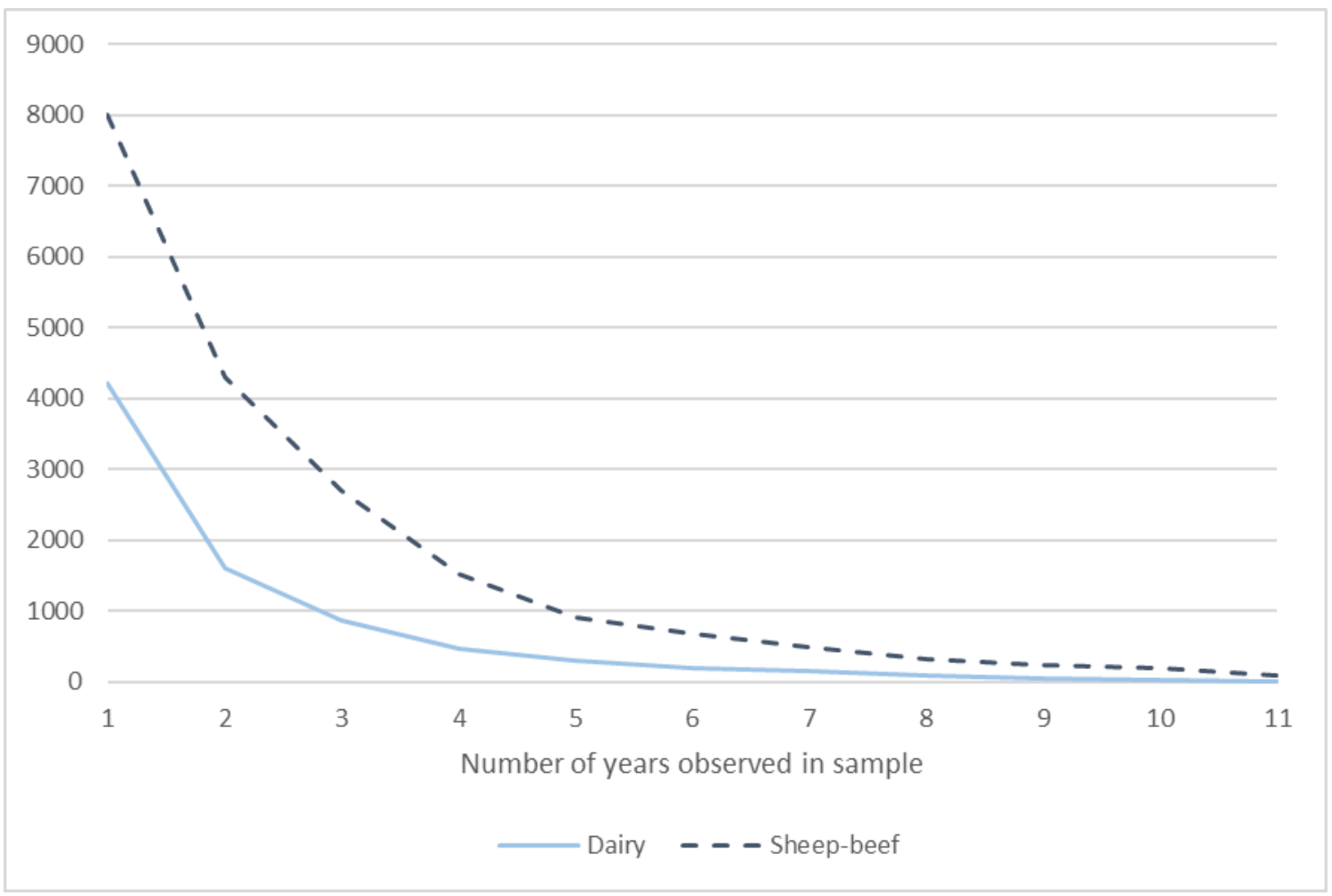

Figure 7 illustrates the pattern of repeat observations: the number of farm enterprises by how many times they appear in the sample. Nearly a quarter of dairy and a sixth of sheep-beef observations are for farm enterprises observed only once in the period 2002-2012. Other farms are observed at least twice, and both sectors include a few farms that are observed in all years, contributing 11 observations each to the sample. Parameters in the fixed effects regressions are estimated from within-firm variation, so firms observed only once do not contribute to the identification of these parameters. ${ }^{15}$

\subsection{Summary statistics}

Summary statistic, presented in Table 1 and graphically for the dependent variables in Figure 8 to Figure 11, support widely held views on differences between farms in the two sectors. The average dairy farm produces more output, is significantly more profitable per unit land area and operates with a higher level of intermediate expenditure than the average sheep-beef farm. More dairy firms take out loans, and they have higher liabilities on average. Less than $20 \%$ of dairy and over $40 \%$ of sheep-beef data points in our sample are for farms that made a net loss in the year of observation. In fact, the average (unweighted mean) profit per hectare is negative for

\footnotetext{
${ }^{15}$ To be precise, firms with a single observation are still used in the estimation of the constant. These firms are therefore included in the reported number of observations in the estimation tables.
} 
sheep-beef firms across the entire sample. A small proportion, around $6 \%$, of firms in both sectors had negative equity in the previous financial year.

Table 1. Summary statistics (pooled across all years)

\begin{tabular}{|c|c|c|c|c|c|c|}
\hline & \multicolumn{3}{|c|}{ Dairy } & \multicolumn{3}{|c|}{ Sheep-beef } \\
\hline & Median & Mean & St. dev. & Median & Mean & St. dev. \\
\hline Gross output (\$1000) & 357.75 & 497.77 & 487.87 & 111.63 & 208.23 & 279.43 \\
\hline Profit/ha & 62.57 & 112.41 & 239.06 & 4.12 & -10.07 & 246.60 \\
\hline Current loans $(\$ 1000)$ & 1.30 & 48.22 & 111.72 & 0.00 & 32.33 & 81.65 \\
\hline Intermediate expenditure $(\$ 1000)$ & 205.21 & 310.92 & 346.91 & 74.10 & 143.01 & 199.68 \\
\hline Drought intensity (PED) & 185.53 & 206.54 & 135.69 & 214.28 & 240.93 & 152.89 \\
\hline Last year's PED & 244.72 & 246.52 & 134.19 & 262.08 & 274.18 & 157.61 \\
\hline Drought extent & 0.00 & 0.03 & 0.04 & 0.00 & 0.03 & 0.04 \\
\hline Prob. of low rainfall & 28.33 & 29.92 & 7.44 & 30.00 & 31.21 & 7.41 \\
\hline MB share of fine texture soil & 0.66 & 0.58 & 0.39 & 0.39 & 0.45 & 0.37 \\
\hline MB average slope & 1.52 & 3.58 & 4.81 & 5.61 & 6.30 & 5.62 \\
\hline TA share of dairy output & 0.65 & 0.63 & 0.23 & 0.36 & 0.38 & 0.23 \\
\hline Distance to city & 37.21 & 42.19 & 25.97 & 36.63 & 43.22 & 30.79 \\
\hline Had loan in previous year ${ }^{*}$ & 1.00 & 0.51 & 0.50 & 0.00 & 0.43 & 0.50 \\
\hline Net loss in previous year ${ }^{*}$ & 0.00 & 0.20 & 0.40 & 0.00 & 0.40 & 0.49 \\
\hline Negative equity in previous year ${ }^{*}$ & 0.00 & 0.06 & 0.23 & 0.00 & 0.06 & 0.24 \\
\hline Productive area (100ha) & 9.00 & 12.62 & 12.72 & 9.15 & 33.12 & 126.35 \\
\hline Share of potentially irrigated land & 0.00 & 0.08 & 0.23 & 0.00 & 0.03 & 0.16 \\
\hline Fertiliser intensity & 0.62 & 0.76 & 0.69 & 0.15 & 0.33 & 0.76 \\
\hline Effluent intensity & 0.09 & 0.12 & 0.15 & 0.00 & 0.00 & 0.04 \\
\hline
\end{tabular}

Notes: dependent variables are shown in bold font, indicator variables are marked with an asterisk $(*)$.

Summary statistics for weather and geographic variables confirm that dairy farms tend to be located in wetter areas (meshblocks with lower average drought intensity readings), meshblocks with a higher share of fine textured soil and a lower average slope. These results are consistent with the sector's demand for high-quality, high-productivity pasture. Reflecting the spatial concentration of the industry, dairy farms are evidently located in TAs where dairy constitutes a higher share of total pastoral output. There are, however, no clear differences in location relative to cities across dairy and sheep-beef farms in our sample.

The average productive land area of dairy farms is smaller, but the distribution of sheepbeef farms' area is wider and more skewed to the right, reflecting high heterogeneity within the sector. A larger share of dairy land is potentially irrigated, though the average share of such land is still relatively low at about $8 \% .{ }^{16}$ Finally, dairy farmers apply fertiliser and effluent at a higher rate than sheep and beef farmers.

\footnotetext{
${ }^{16}$ Note that the summary statistics are for pooled (across years) data and they are unweighted by land area, so figures in Table 1 may not accurately portray the overall share of irrigated land across the sectors. However, we find that weighted
} 
Figure 8 to Figure 11 depict the (unweighted) sectoral means of each dependent variable over time. Some of these graphs have troughs in the census years of 2002, 2007 and 2012 because a higher number of small farms, underrepresented in the intervening surveys, are included in the sample in those years. However, these variations in sample composition do not affect our estimation results which rely on within-farm variation to identify the impact of droughts on these variables.

Figure 8. Mean gross output by sector $(\$ 1000)$

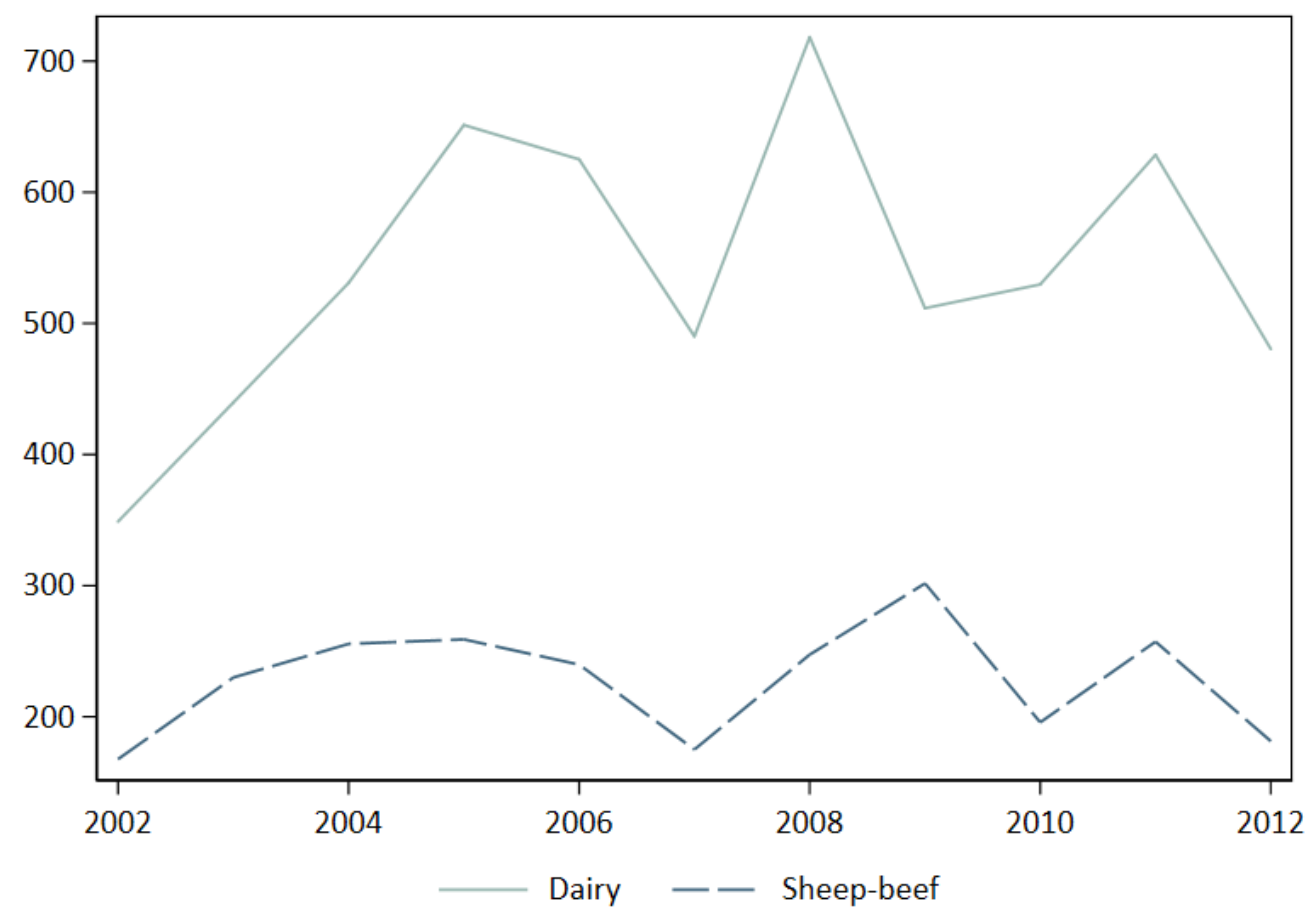

irrigation shares ( $10 \%$ and below $2 \%$ for dairy and sheep-beef, respectively) are close to the unweighted values shown in Table 1, and we also find no evidence for clear trends in the proportion of potentially irrigated land over time in our sample. 
Figure 9. Mean profit per hectare by sector (\$)

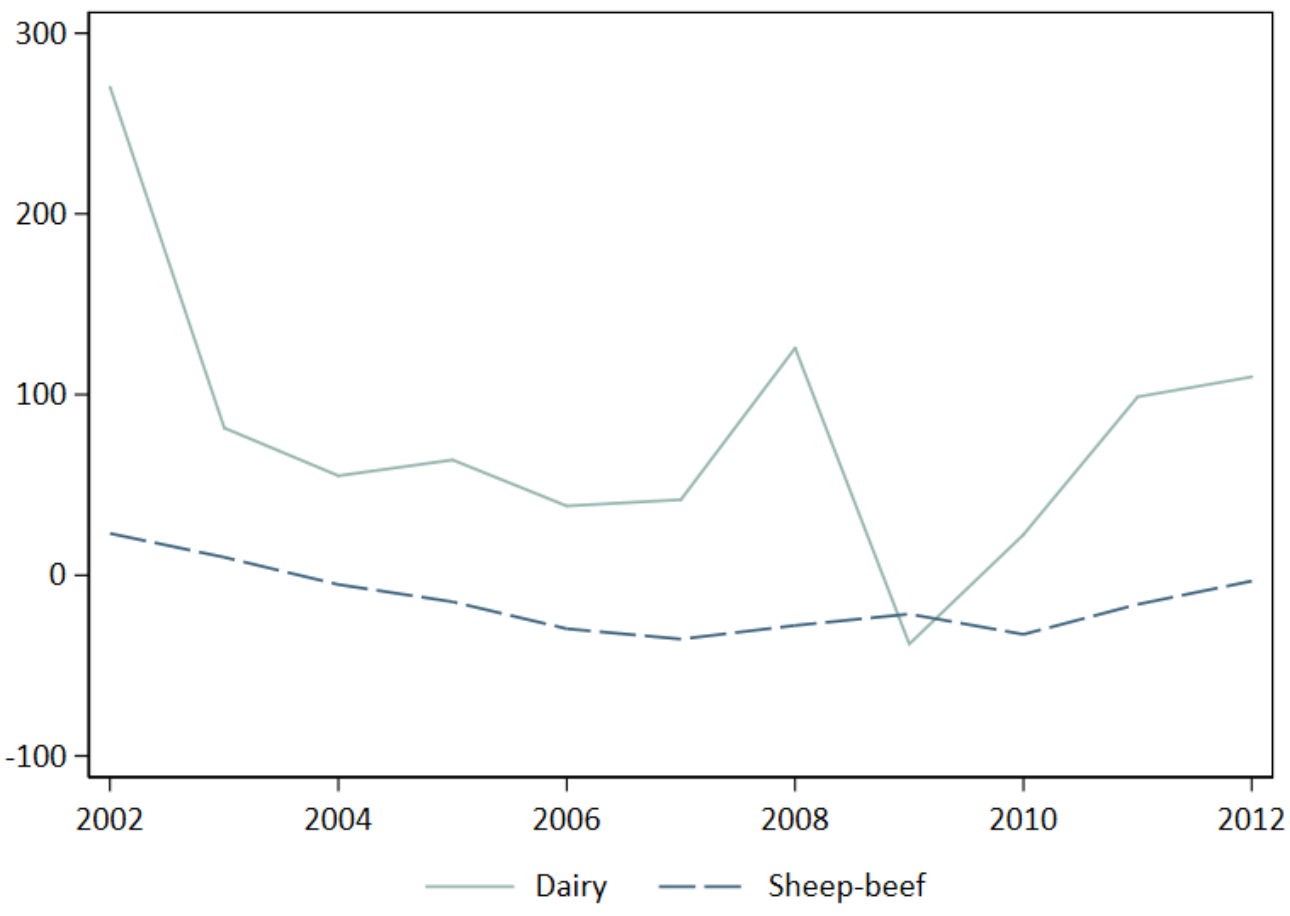

Figure 10. Mean current loans by sector $(\$ 1000)$

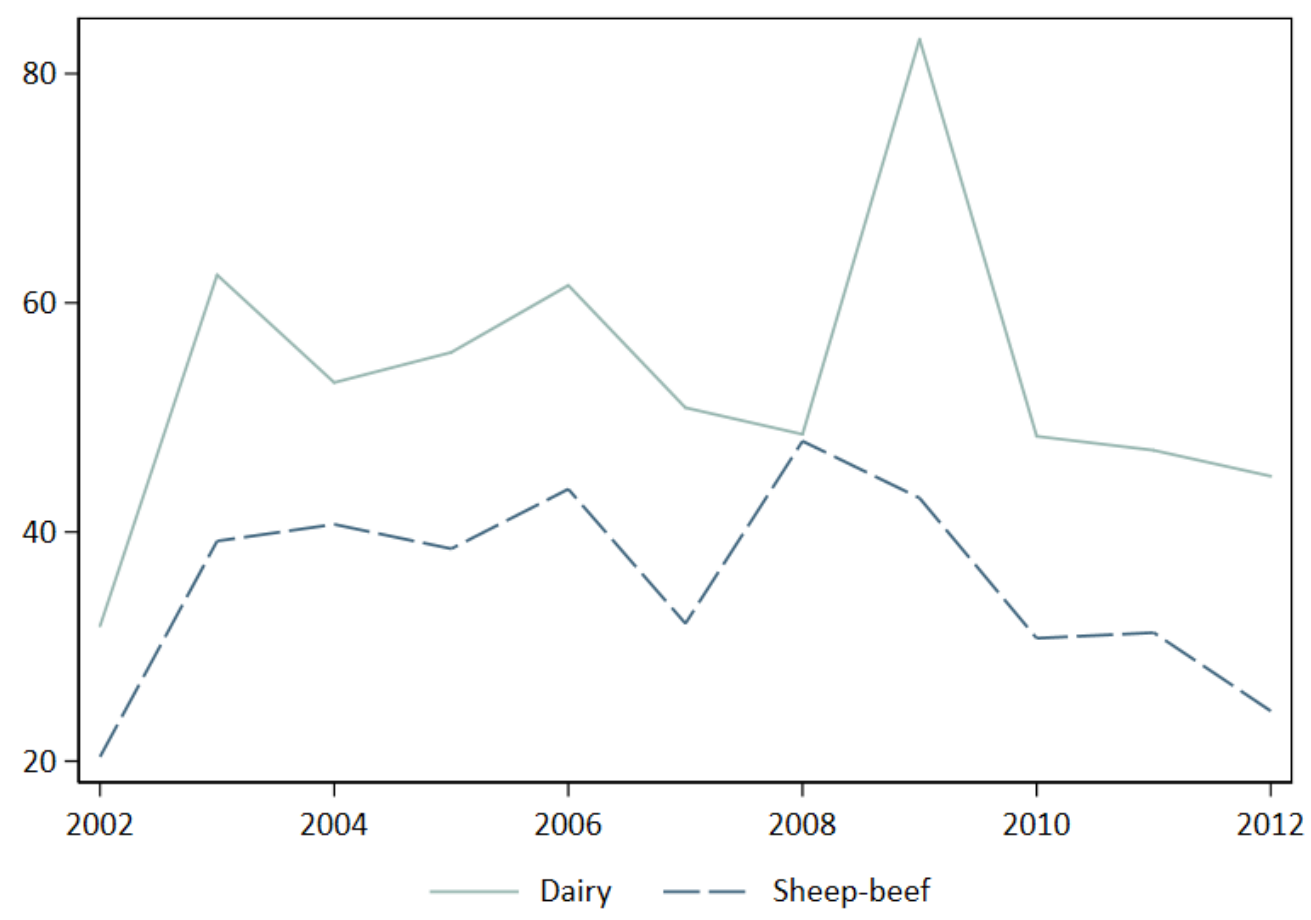


Figure 11. Mean intermediate expenditures by sector $(\$ 1000)$

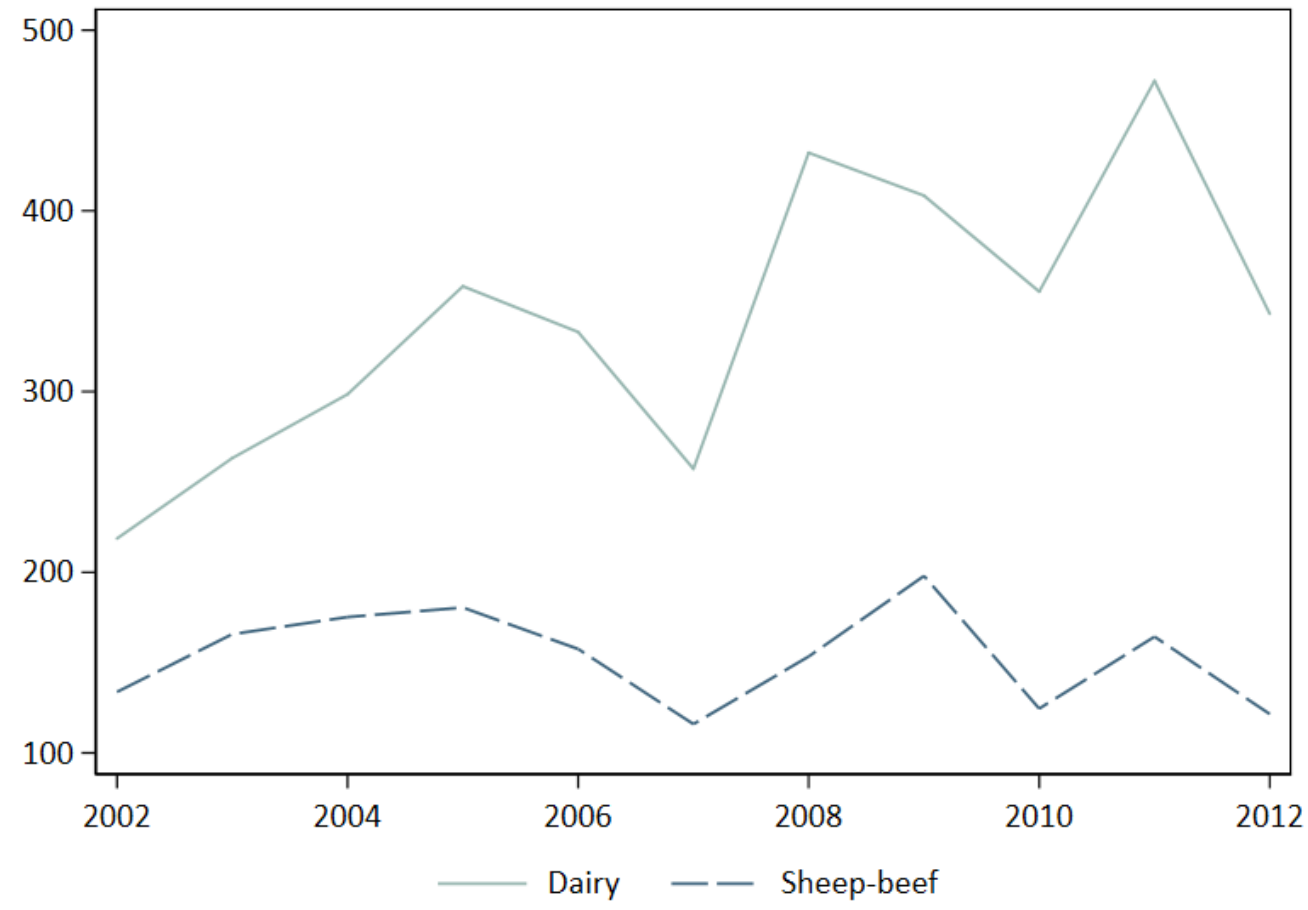

Figure 9 illustrates that 2008, the year of a severe drought in the largest dairy region in the country, Waikato, was a notably good year for the sector. Conversely, the following year is associated with the lowest average profits per hectare for dairy, despite relatively favourable weather conditions in much of the country. These events were driven by coincidental developments in international commodity markets as a result of which milk solid prices peaked in 2008 before diving sharply in the following year (Butcher Partners, 2009). In our regressions, the time fixed effects pick up such changes in outcomes driven by commodity prices.

\section{$5 \quad$ Discussion of estimation results}

Table 2 and Table 3 contain fixed effects regression results for gross output, profit per hectare, current loans and intermediate expenditure for dairy and sheep-beef farms, respectively. Each outcome is assessed by three model specifications with an increasing set of explanatory variables. Other than the constant and a complete set of time and farm fixed effects, the basic specification includes only a quadratic effect for drought intensity. Building on this, the extended specification also includes the remaining drought-related variables and other explanatory variables characterising the farm's geographical location and previous financial status. Interaction terms between these variables and drought intensity, highlighted in the table, enable us to estimate a differential drought impact for farms with certain characteristics. Lastly, the complete specification incorporates our full set of explanatory variables, including those 
associated with farm management. Parameter estimates of time and farm fixed effects are omitted from the tables. The overall impact of drought intensity on the outcome variable can be difficult to assess due to the non-linearity in PED and the large number of interaction terms, so the estimated marginal effect is included near the bottom of both tables. We discuss these results by sector, first focusing on the main drought effects and then extending the discussion to the interaction terms from the more complex specifications.

\subsection{Dairy farming}

The estimated marginal effects from the basic model specifications show that for dairy farms, a $1 \%$ increase in drought intensity is associated with a $0.04 \%$ fall in gross output, a $\$ 6.65$ fall in net profit per hectare, a $0.32 \%$ increase in current loans taken out by the farm and a $0.03 \%$ fall in intermediate expenditure. All of these marginal effects are significant at the $1 \%$ level. For the average dairy farm (i.e., at the sample mean), they roughly correspond to a $\$ 194$ decrease in gross output, a $\$ 6.65$ fall in net profit per hectare, a $\$ 152$ increase in current loans and an $\$ 81$ decrease in intermediate expenditure resulting from a $2 \mathrm{~mm}$ shortfall in precipitation. Although most of these effects may seem relatively minor, a severe drought, such as the one that hit Waikato in 2008 , can be associated with a $100 \%$ (or larger) increase in PED relative to a normal year. All else equal, an increase of this magnitude would imply a loss of about $\$ 13,408$ in gross output, a fall by $\$ 466$ in profit per hectare, an increase of $\$ 11,876$ in current loans and a fall by $\$ 5,608$ in intermediate expenditure relative to a normal year for the average dairy farm (according to the basic model specification). ${ }^{17}$

\footnotetext{
${ }^{17}$ Rather than simply multiplying the estimated marginal effects by 100 , these impacts have been extrapolated by taking compounding into account.
} 
Table 2. Estimation results for dairy

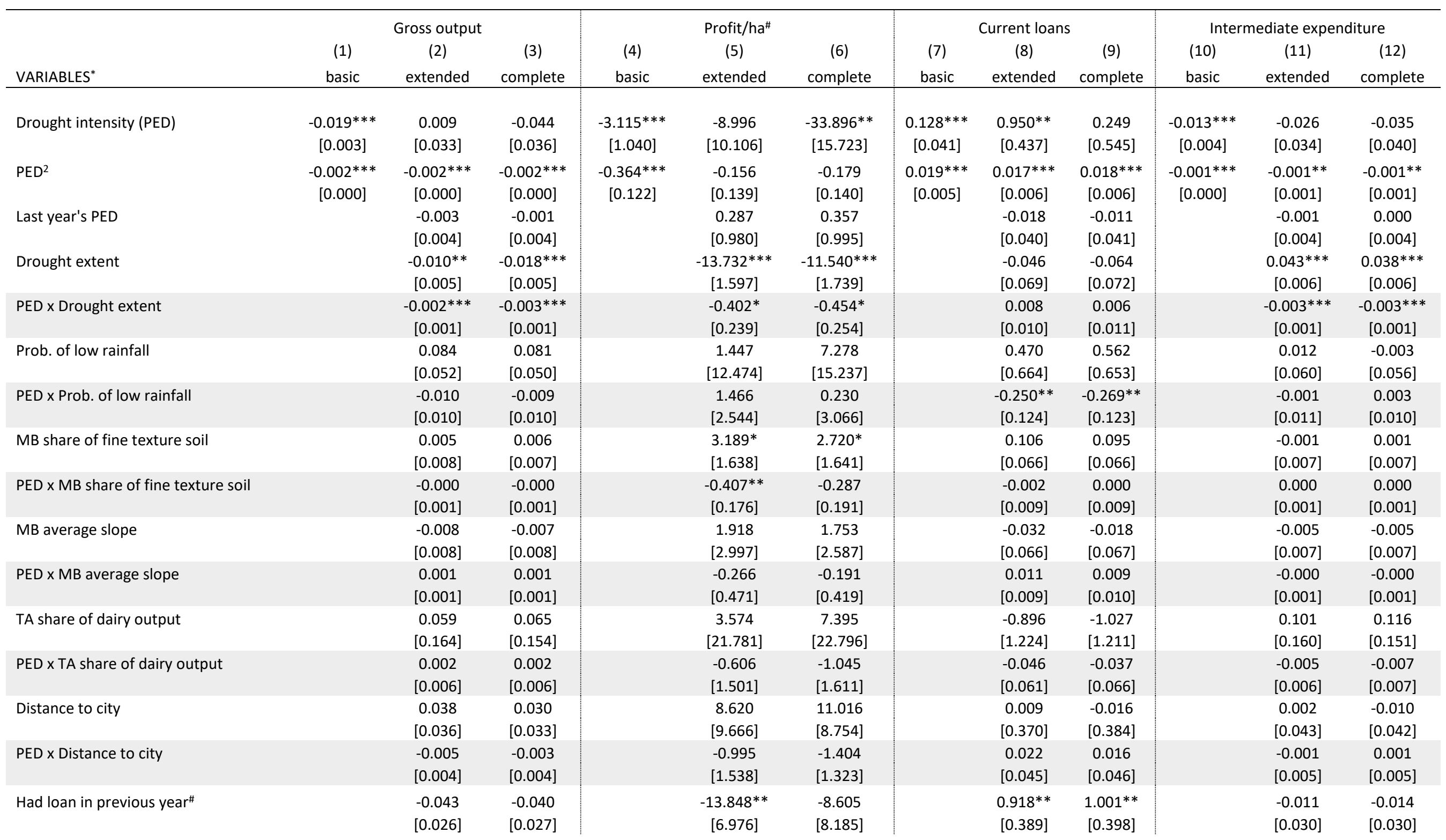




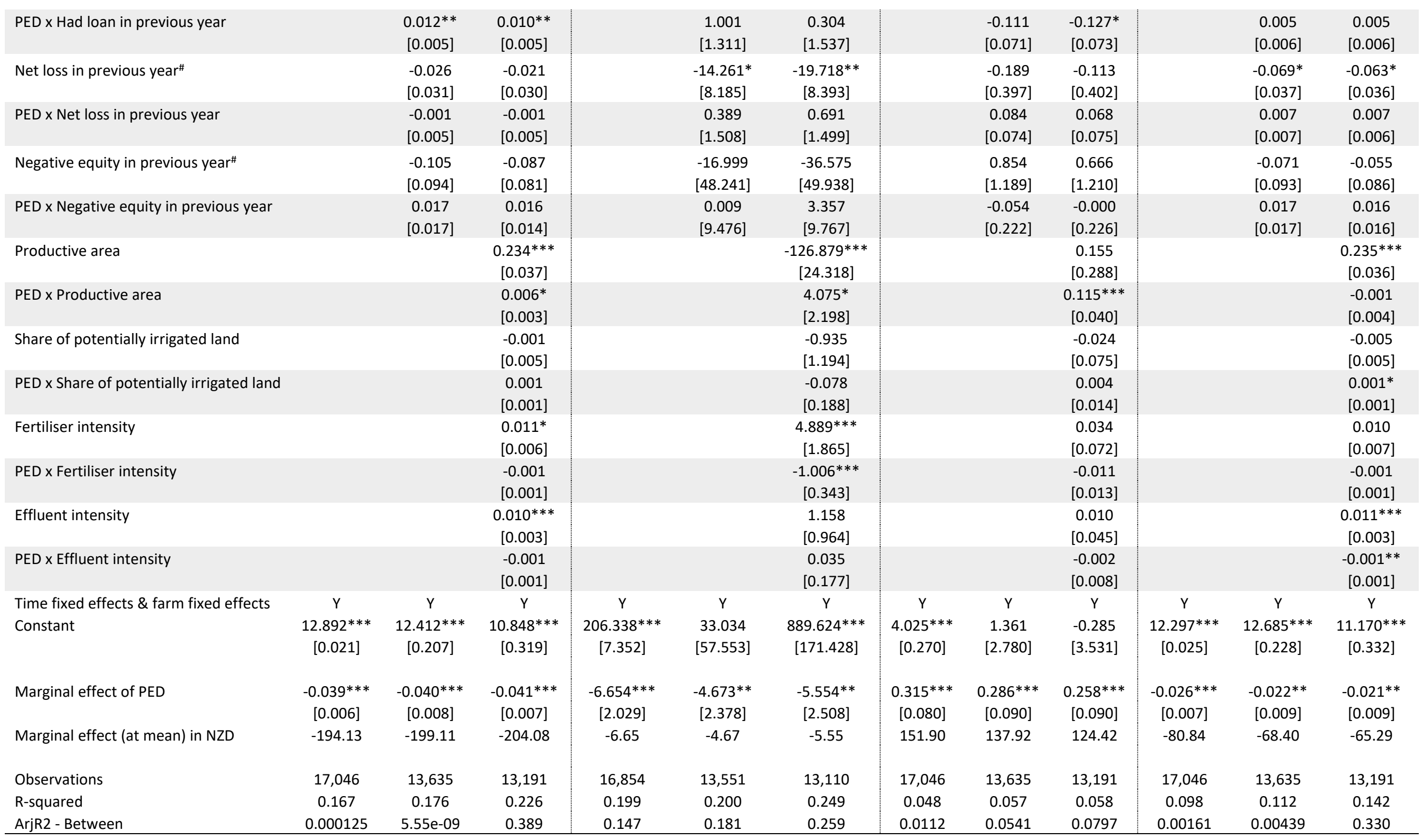

Robust standard errors in brackets $* * * p<0.01, * * p<0.05, * p<0.1$

${ }^{*}$ All variables, except those marked with \#, are in natural logs 
The direction of the estimated drought effects on gross output, profit per hectare and current loans matches prior expectations. However, we expected intermediate expenditure to rise as part of dairy farmers' drought response, yet we estimate a negative marginal effect (consistently in all three specifications). This could happen in theory if, in order to offset the increase in costs associated with purchasing supplementary feed, dairy farmers reduced spending on other components of intermediate expenditure (such as spending on repairs and maintenance, payments made to contractors and related parties or spending on other items) by even more. ${ }^{18}$ Nonetheless, given what we know of dairy sector drought responses from previous research and the apparent increase in loans taken out by dairy farmers during droughts in our own results, we admit this falls short of a conclusive explanation. Finally, we also note that in the context of other estimates and the mean level of the variable in the sector, the magnitude of the estimated effect on profit per hectare is relatively large (even bearing in mind that incidences of negative profit are not uncommon among dairy farms in our sample).

Estimated effects for drought intensity from the extended and complete model specifications are consistent with those from the basic model. In addition to assessing these main drought effects on farm outcomes, through the interaction terms these specifications allow us to evaluate how farms with different characteristics cope in droughts.

The majority of the additional parameter estimates in these specifications are not statistically significant. Before examining them more closely, we note that several of the individual (non-interaction) terms are included for statistical control only, and we do not consider them economically meaningful in the context of our estimation strategy. For instance, while distance to the nearest city might influence a farm's day-to-day operations, in most cases the farm fixed effect in our estimation already accounts for this (as well as for all other unchanging characteristics of the farm). The parameter for distance to nearest city is identified only from instances where there is a change in distance across repeated observations of the same farm. This can happen in the cases, mentioned in section 4.4 on sample construction, where there is a change over time in the meshblock of the farm enterprise within the same region. The same basic logic applies to parameters of other individual terms, though some carry

\footnotetext{
${ }^{18}$ To assess the plausibility of this explanation, we also considered a more narrowly defined expenditure variable, the 'other expenses' component of intermediate expenditure, as an alternative outcome. However, results for other expenses did not fundamentally differ from those for intermediate expenditure, and in particular, the estimated marginal effect of drought intensity remained negative. We note that purchases of stock feed is just one of over a hundred possible items listed under other expenses by IRD, so it is still theoretically possible that farmers reduce spending on other items within the category.
} 
more economic meaning than others. For example, while the fixed effect also controls for the average size of productive land area of a farm, productive area can change from year to year more freely due to farm management decisions or transfers of land. Therefore, within-farm variations in productive area both happen more frequently and are more meaningful than within-farm variations in distance to nearest city (or MB average slope, TA share of dairy output, et cetera).

First we discuss variables associated with weather. We do not find evidence for drought impacts stretching across multiple years for dairy: the parameter estimate for last year's drought intensity is not statistically significant for any of the dependent variables. On the other hand, the spatial extent of the current drought seems to matter to all dairy farms, whether or not they are actually experiencing a drought at their location: a larger drought is associated with lower gross output, lower profit per hectare and higher intermediate expenditure for all dairy farms in general. These findings could reflect general equilibrium effects whereby local demand rises sufficiently to affect input cost and adaptation opportunities in droughts affecting large areas of the country. In addition, the estimates of the interaction term between drought intensity and drought extent indicate that for those farms experiencing higher drought intensities, the spatial extent of the drought generally further increases the effect of the drought itself. So for a given local drought intensity, the larger the geographic extent of the drought, the larger is the decrease in gross output, profit per hectare and intermediate expenditure. Lastly, there is only limited evidence in our estimates for the hypothesis that farmers are more severely hit by unexpected droughts: for a given drought intensity, the higher the probability of low rainfall for the region in NIWA's long-term weather outlook (i.e., the more expected the drought is), the smaller the increase in current loans taken out by farms. This effect is statistically significant at the $5 \%$ level. However, other farm outcomes are unaffected. It may be that the granularity of the outlook variable is too low spatially as well as in terms of range, and that farmers may ignore it or combine it with other information to form their expectations for the upcoming season.

Characteristics associated with the geographic location of the farm, such as soil texture and slope within the meshblock, the distance to the nearest city (from the meshblock centroid) or the share of dairy output in the TA, do not appear to systematically affect the impact of drought intensity on dairy farms, as evidenced by the parameter estimates of their respective interaction effects. 
Dairy farms with positive bank loans in the previous financial year tend to have higher loans in the current year. Similarly, farms with net losses in the previous year tend to have lower profits this year. Due to the inclusion of fixed effects in our estimation, these results do not relate to comparisons of different farms. Rather, they reflect some level of persistence of outcomes within the same farm. Considering the interaction effects, the results suggest that farms with bank loans in the previous year were able to produce slightly more gross output in a drought year (compared to farms who did not have loans). This may be because of underlying differences in farms that take out loans versus those that do not. However, drought impacts for these groups of farms are not significantly different in terms of the other dependent variables. There is also no difference based on previous losses or negative equity, so the evidence for the importance of previous financial state, as reflected in our data and variables, in dairy farms' ability to cope with droughts is fairly weak.

Results from the complete model specification also show the expected relationship that farms increasing their productive area produce more output and have higher intermediate expenditure. They also seem less profitable which may reflect fixed costs associated with increasing productive area. The interaction of productive area and drought intensity suggests that larger farms borrow more in droughts, and there appears some weak evidence that they are less severely affected in terms of profits or output. Surprisingly, we find no significant effect on any outcome from (potential) irrigation: farms with a higher share of irrigated land fare no better in droughts. We attribute this finding to the patchiness and inconsistency of the irrigation data, and note that others using similar data have also failed to identify a significant effect on farm outcomes (Fabling \& Morris, 2013; Pourzand et al., 2020). ${ }^{19}$

Increasing fertiliser intensity is associated with increasing profitability and, more weakly, with increasing gross output. We also find some evidence that higher land-use intensity, as reflected in the fertiliser and effluent intensity of the dairy farm, compounds some of the drought impacts previously noted. Specifically, our estimates suggest that farms with a higher fertiliser intensity experience a larger reduction in profits, and farms with a higher effluent intensity experience a larger reduction in intermediate expenditure in years with higher drought intensity.

\footnotetext{
${ }^{19}$ Recall from the discussion of variables that questions about irrigation were not asked in all years, nor in a consistent manner in the APS. Fabling and Morris investigate the effect of irrigation on productivity, but not specifically in droughts; Pourzand et al. find no evidence for irrigation being a mitigating factor for drought effects on farm revenue and operating profit (but note a small effect on balance-sheet indicators). On the other hand, using data on farm sales and valuations in a hedonic study, Grimes and Aitken (2008) demonstrate that water consents are valuable, and they are more valuable in drier areas.
} 


\subsection{Sheep and beef farming}

For sheep-beef farms, as shown in Table 3, a 1\% increase in drought intensity is found in the basic specification to be associated with a roughly $0.03 \%$ decrease in gross output and about the same proportional decrease in intermediate expenditure, but no significant change in profit per hectare or current bank loans. The negative marginal effects for output and intermediate expenditure are significant at the $1 \%$ level, and they are consistent across all model specifications. Expressed in dollar terms, they correspond to reductions of $\$ 56$ in gross output and of \$41 in intermediate expenditure for a $2.4 \mathrm{~mm}$ increase in PED. For a doubling of drought intensity, these effects correspond to relatively modest annual reductions of $\$ 3899$ in gross output and \$2874 in intermediate expenditure for the average sheep-beef farm (calculated in the same way as for dairy).

While we cannot directly observe destocking in our data, the findings could be consistent with such behaviour during episodes of drought. Gross output falls as it is measured net of changes in stock value-so any additional sales generated by destocking are offset by the reduction in breeding stock numbers and, potentially, the decline in stock quality. Profits (per hectare) are not significantly affected because, the results suggest, with falling gross output, sheep-beef farmers also reduce their spending. Due to these factors and the cash flow from destocking, droughts are also less likely to affect borrowing by sheep-beef farmers.

Similarly to dairy, most of the parameter estimates from the extended and complete specifications are not statistically significant. The previous caveats and discussion around the interpretation of the individual (non-interaction) effects apply equally to sheep-beef estimates. Therefore, we focus the analysis of sheep-beef results more tightly on the interaction effects, especially where the estimates are statistically significant and consistent across specifications, or where they differ from dairy results in important ways.

Consistent with other findings (Bevin, 2007), our results indicate that droughts can have longer-lasting impacts on sheep-beef farms. High drought intensity in the previous year has a negative effect on gross output this year. There is some indication that profits are also reduced a year down the line. Similar to our findings for dairy, the parameter estimates for drought extent indicate that drought effects may spill over to those farmers not directly experiencing drought conditions - this can happen through changes in market prices. With regard to its interaction terms, the results that for a given local drought intensity, a spatially more extensive drought is associated with a further reduction in output and in intermediate expenditure are consistent with effects operating through changes in market prices. On the other hand, the 
finding that profits of drought-affected farms go up with spatial extent, as suggested by the positive estimate of the interaction term, is unexpected.$^{20}$ The final significant weather-related interaction effect suggests that sheep-beef farmers decrease intermediate expenditure further when droughts are more expected, that is, when low rainfall had been forecast with a higher probability. This may reflect the value of preparation and early action.

${ }^{20}$ As noted before, one way in which some sheep-beef farmers could conceivably benefit from droughts is if they are able to sell fodder or grazing rights to dairy farmers at inflated prices. But this opportunity would not be constrained to droughtaffected sheep and beef farmers - unless close proximity to affected dairy farms is essential. However, the estimates suggest that drought effects on most outcomes of sheep-beef farms do not significantly depend on the share of dairy in the $\mathrm{TA}$, so we consider such cross-sectoral interactions a relatively unlikely explanation here. 
Table 3. Estimation results for sheep-beef

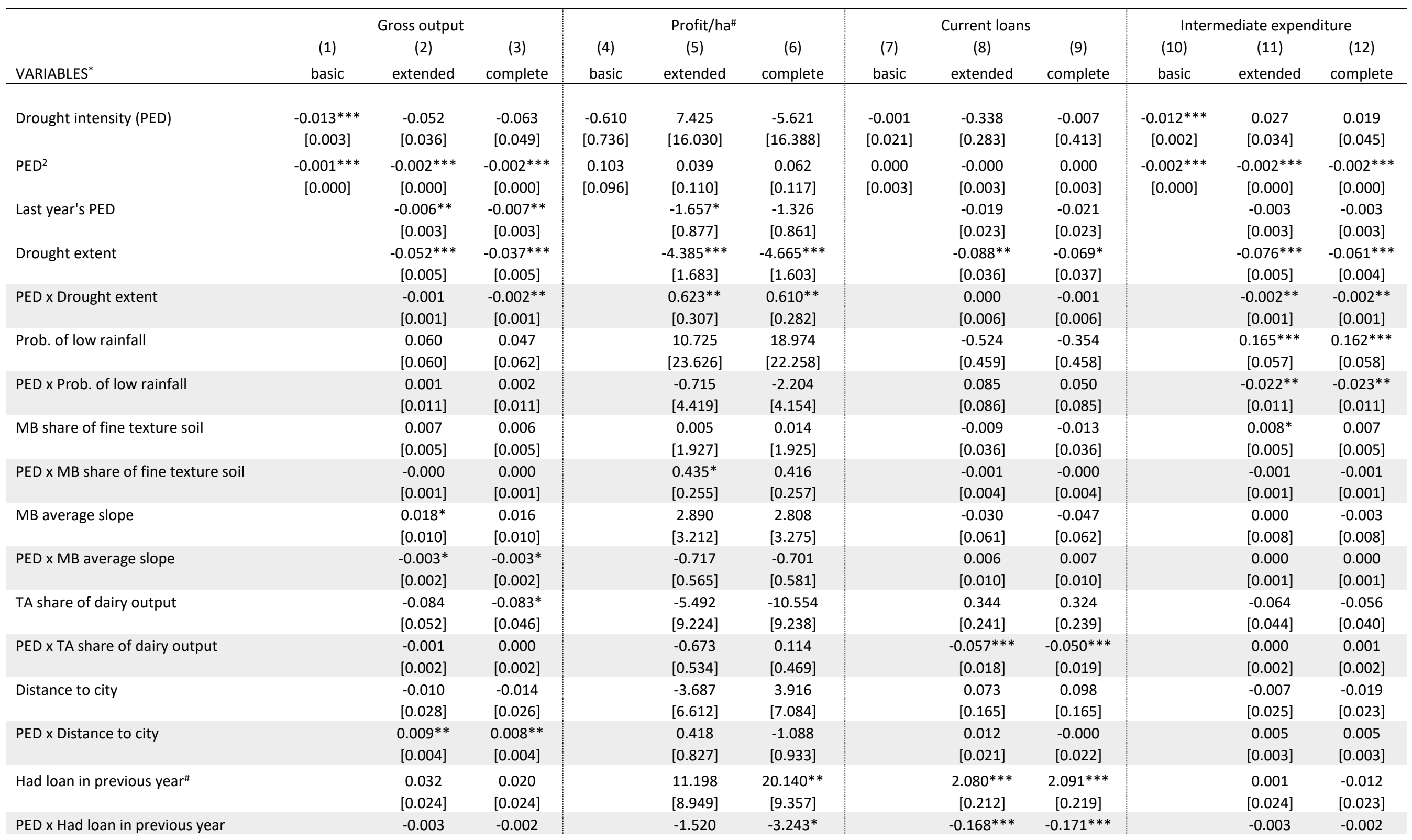


A Growing Problem: Exploring Livestock Farm Resilience to Droughts in Unit Record Data

\begin{tabular}{|c|c|c|c|c|c|c|c|c|c|c|c|c|}
\hline & & {$[0.004]$} & [0.004] & & [1.642] & [1.731] & & [0.038] & {$[0.040]$} & & [0.004] & [0.004] \\
\hline Net loss in previous year\# & & $\begin{array}{c}-0.131 * * * \\
{[0.031]}\end{array}$ & $\begin{array}{c}-0.147^{* * *} \\
{[0.028]}\end{array}$ & & $\begin{array}{c}0.944 \\
{[12.313]}\end{array}$ & $\begin{array}{l}-14.347 \\
{[9.387]}\end{array}$ & & $\begin{array}{c}0.164 \\
{[0.189]}\end{array}$ & $\begin{array}{c}0.065 \\
{[0.207]}\end{array}$ & & $\begin{array}{c}-0.114 * * * \\
{[0.025]}\end{array}$ & $\begin{array}{c}-0.114^{* * *} \\
{[0.026]}\end{array}$ \\
\hline PED $x$ Net loss in previous year & & $\begin{array}{c}0.006 \\
{[0.006]}\end{array}$ & $\begin{array}{c}0.010 * * \\
{[0.005]}\end{array}$ & & $\begin{array}{l}-3.706 \\
{[2.287]}\end{array}$ & $\begin{array}{l}-1.030 \\
{[1.704]}\end{array}$ & & $\begin{array}{l}-0.026 \\
{[0.034]}\end{array}$ & $\begin{array}{c}-0.004 \\
{[0.037]}\end{array}$ & & $\begin{array}{c}0.010^{* *} \\
{[0.004]}\end{array}$ & $\begin{array}{c}0.011^{* *} \\
{[0.005]}\end{array}$ \\
\hline Negative equity in previous year ${ }^{\#}$ & & $\begin{array}{c}0.058 \\
{[0.058]}\end{array}$ & $\begin{array}{c}0.050 \\
{[0.062]}\end{array}$ & & $\begin{array}{c}-9.069 \\
{[12.018]}\end{array}$ & $\begin{array}{c}5.760 \\
{[11.518]}\end{array}$ & & $\begin{array}{c}0.821 \\
{[0.589]}\end{array}$ & $\begin{array}{c}0.914 \\
{[0.604]}\end{array}$ & & $\begin{array}{l}-0.082 \\
{[0.056]}\end{array}$ & $\begin{array}{l}-0.093 \\
{[0.057]}\end{array}$ \\
\hline PED $\times$ Negative equity in previous year & & $\begin{array}{l}-0.016 \\
{[0.010]}\end{array}$ & $\begin{array}{l}-0.017 \\
{[0.011]}\end{array}$ & & $\begin{array}{c}0.620 \\
{[2.412]}\end{array}$ & $\begin{array}{l}-2.264 \\
{[2.342]}\end{array}$ & & $\begin{array}{l}-0.100 \\
{[0.106]}\end{array}$ & $\begin{array}{c}-0.129 \\
{[0.109]}\end{array}$ & & $\begin{array}{c}0.006 \\
{[0.010]}\end{array}$ & $\begin{array}{c}0.006 \\
{[0.010]}\end{array}$ \\
\hline Productive area & & & $\begin{array}{c}0.256^{* * *} \\
{[0.018]}\end{array}$ & & & $\begin{array}{c}-25.163 * * * \\
{[8.794]}\end{array}$ & & & $\begin{array}{c}0.503^{* * *} \\
{[0.100]}\end{array}$ & & & $\begin{array}{c}0.214 * * * \\
{[0.015]}\end{array}$ \\
\hline PED $\times$ Productive area & & & $\begin{array}{c}0.002 \\
{[0.002]}\end{array}$ & & & $\begin{array}{c}2.931^{* * *} \\
{[1.086]}\end{array}$ & & & $\begin{array}{l}0.025^{*} \\
{[0.013]}\end{array}$ & & & $\begin{array}{c}0.000 \\
{[0.002]}\end{array}$ \\
\hline Share of potentially irrigated land & & & $\begin{array}{c}0.024^{* *} \\
{[0.011]}\end{array}$ & & & $\begin{array}{c}2.281 \\
{[2.683]}\end{array}$ & & & $\begin{array}{c}-0.164 \\
{[0.107]}\end{array}$ & & & $\begin{array}{l}0.019^{*} \\
{[0.010]}\end{array}$ \\
\hline PED $\times$ Share of potentially irrigated land & & & $\begin{array}{c}-0.002 \\
{[0.002]}\end{array}$ & & & $\begin{array}{l}-0.247 \\
{[0.468]}\end{array}$ & & & $\begin{array}{c}0.029 \\
{[0.019]}\end{array}$ & & & $\begin{array}{c}-0.001 \\
{[0.002]}\end{array}$ \\
\hline Fertiliser intensity & & & $\begin{array}{c}0.002 \\
{[0.003]}\end{array}$ & & & $\begin{array}{l}-0.452 \\
{[0.961]}\end{array}$ & & & $\begin{array}{c}0.002 \\
{[0.021]}\end{array}$ & & & $\begin{array}{c}0.014 * * * \\
{[0.003]}\end{array}$ \\
\hline PED $x$ Fertiliser intensity & & & $\begin{array}{c}0.001 \\
{[0.001]}\end{array}$ & & & $\begin{array}{c}0.088 \\
{[0.176]}\end{array}$ & & & $\begin{array}{c}-0.002 \\
{[0.004]}\end{array}$ & & & $\begin{array}{l}-0.001^{*} \\
{[0.000]}\end{array}$ \\
\hline Effluent intensity & & & $\begin{array}{l}-0.005 \\
{[0.010]}\end{array}$ & & & $\begin{array}{c}0.919 \\
{[2.200]}\end{array}$ & & & $\begin{array}{l}-0.040 \\
{[0.092]}\end{array}$ & & & $\begin{array}{l}-0.000 \\
{[0.009]}\end{array}$ \\
\hline PED x Effluent intensity & & & $\begin{array}{c}0.002 \\
{[0.002]}\end{array}$ & & & $\begin{array}{l}-0.024 \\
{[0.489]}\end{array}$ & & & $\begin{array}{c}0.004 \\
{[0.017]}\end{array}$ & & & $\begin{array}{c}0.001 \\
{[0.002]}\end{array}$ \\
\hline Time fixed effects $\&$ farm fixed effects & Y & Y & $\mathrm{Y}$ & Y & Y & $\mathrm{Y}$ & Y & Y & $\mathrm{Y}$ & Y & Y & $\mathrm{Y}$ \\
\hline Constant & $\begin{array}{c}11.499 * * * \\
{[0.018]}\end{array}$ & $\begin{array}{c}10.803^{* * *} \\
{[0.231]}\end{array}$ & $\begin{array}{c}9.509 * * * \\
{[0.297]}\end{array}$ & $\begin{array}{c}10.406 * * \\
{[4.551]}\end{array}$ & $\begin{array}{c}-45.484 \\
{[93.964]}\end{array}$ & $\begin{array}{l}101.249 \\
{[99.796]}\end{array}$ & $\begin{array}{c}4.219 * * * \\
{[0.145]}\end{array}$ & $\begin{array}{c}4.601^{* * *} \\
{[1.646]}\end{array}$ & $\begin{array}{l}-1.379 \\
{[2.385]}\end{array}$ & $\begin{array}{c}11.344 * * * \\
{[0.017]}\end{array}$ & $\begin{array}{c}10.056^{* * *} \\
{[0.210]}\end{array}$ & $\begin{array}{c}9.100 * * * \\
{[0.269]}\end{array}$ \\
\hline Marginal effect of PED & $\begin{array}{c}-0.027^{* * *} \\
{[0.005]}\end{array}$ & $\begin{array}{c}-0.030 * * * \\
{[0.007]}\end{array}$ & $\begin{array}{c}-0.031 * * * \\
{[0.007]}\end{array}$ & $\begin{array}{c}0.444 \\
{[1.313]}\end{array}$ & $\begin{array}{c}0.654 \\
{[1.698]}\end{array}$ & $\begin{array}{l}-1.231 \\
{[1.904]}\end{array}$ & $\begin{array}{c}0.001 \\
{[0.043]}\end{array}$ & $\begin{array}{l}-0.013 \\
{[0.050]}\end{array}$ & $\begin{array}{c}-0.014 \\
{[0.050]}\end{array}$ & $\begin{array}{c}-0.029 * * * \\
{[0.005]}\end{array}$ & $\begin{array}{c}-0.036^{* * *} \\
{[0.006]}\end{array}$ & $\begin{array}{c}-0.037^{* * *} \\
{[0.006]}\end{array}$ \\
\hline Marginal effect (at mean) in NZD & -56.22 & -62.47 & -64.55 & 0.44 & 0.65 & -1.23 & 0.32 & -4.20 & -4.53 & -41.47 & -51.48 & -52.91 \\
\hline Observations & 50,199 & 38,055 & 37,200 & 49,230 & 37,599 & 36,774 & 50,199 & 38,055 & 37,200 & 50,199 & 38,055 & 37,200 \\
\hline R-squared & 0.025 & 0.036 & 0.087 & 0.015 & 0.022 & 0.025 & 0.009 & 0.027 & 0.033 & 0.066 & 0.075 & 0.120 \\
\hline ArjR2 - Between & $3.85 e-06$ & 0.126 & 0.629 & 0.00817 & 0.0467 & 0.00696 & 0.00667 & 0.438 & 0.353 & 0.000109 & 0.0272 & 0.575 \\
\hline
\end{tabular}

Robust standard errors in brackets *** $p<0.01,{ }^{* *} p<0.05,{ }^{*} p<0.1$

*All variables, except those marked with \#, are in natural logs 
The remaining estimates suggest that in years with higher drought intensity, larger (in terms of land area) sheep-beef farms are more profitable and may borrow more than smaller ones; sheep-beef farms located farther from cities seem to experience a smaller reduction in gross output; sheep-beef farms with previous net losses have relatively higher intermediate expenditure and output; and sheep-beef farms located in TA's with more dairy and those with higher previous bank loans reduce their borrowing. Similar to dairy, we find no effect on drought impacts across farms with different levels of potential irrigation.

Some of these findings are plausible in isolation, but in the context of other estimates, we do not feel they paint a complete picture of differential drought impacts for sheep-beef farms with different observed attributes. A possible explanation is that, despite the tight constraints applied in selecting our estimation sample, our explanatory variables do not capture the full scale of heterogeneity of the sector-outcomes may vary systematically with farm attributes that are unobserved to us. Therefore, our results could reflect average outcomes across multiple types of sheep-beef farms engaging in different drought responses, making it difficult to disentangle the contributing components.

\section{Concluding thoughts}

We have estimated the effect of annual changes in drought intensity on selected economic outcomes of livestock farms using administrative unit-record data and a set of panel regressions. We employ farm fixed effects to control for all time-invariant characteristics of a farm enterprise and year fixed effects to control for macroeconomic shocks affecting all farms. Combined with the exogeneity of weather outcomes, these methods allow for a causal interpretation of the estimated economic effects of droughts.

In constructing the sample, we apply strict conditions to ensure that our estimation data relate to active farm enterprises that can be tied to a livestock sector and a geographic location with a high level of confidence. Our main sample spans an 11-year period and consists of over 67,000 observations of dairy and sheep-beef farms. Of these, nearly 13,000 dairy and around 42,000 sheep-beef observations relate to repeated observations of a farm enterprise through time-these therefore contribute to the estimation of drought impacts in our fixed-effects regressions.

Estimation results suggest that a $1 \%$ increase in drought intensity-corresponding to a 2 $\mathrm{mm}$ shortfall in precipitation or, roughly, half a day of reduced plant growth-causes a \$194 
decrease in gross output, a (relatively large) $\$ 6.65$ fall in net profit per hectare, a $\$ 152$ increase in current loans and an $\$ 81$ decrease in intermediate expenditure for the average dairy farm. The direction of the estimated drought effect on intermediate expenditure is unexpected as previous studies have documented an increase in expenditure as part of dairy farmers' usual drought response.

Regarding the sheep and beef sector, we find that a $1 \%$ increase in drought intensity leads to a $\$ 56$ in fall gross output and a $\$ 41$ fall in intermediate expenditure for the average farm, and we find that gross output may not fully recover for another year following the drought. The estimated marginal effects represent modest impacts considering the empirical distribution of the variables in the sector. (Gross output is adjusted for changes in stock value, so a fall in gross output could be consistent with destocking during drought episodes.) Our estimates for the effect of drought intensity on profit per hectare and current loans of sheep and beef farms are not statistically significant.

For farms experiencing a given local drought intensity, as the spatial extent of the drought increases, the effect on farm-economic outcomes is generally amplified. Moreover, the estimates indicate that droughts may also impact farmers not directly experiencing drought conditions. A plausible way for this to happen is through changes in market prices brought about by changes in supply and demand in large droughts.

We attempt to assess the role of weather expectations by incorporating data from NIWA's long-term weather outlooks. Our results show that, ceteris paribus, the higher the likelihood of low rainfall in weather outlooks, the lower the level of current loans taken out by dairy farmers and the larger the decrease in intermediate expenditure of sheep-beef farmers. While these findings could reflect the value of preparation and early action, we do not find any evidence of impacts on output and profits.

In addition to assessing the effect of drought-related variables on farm-economic outcomes, we test whether the estimates change with different farm characteristics. In order to do so, we introduce additional specifications with interaction terms between drought intensity and various explanatory variables relating to the geographic location, financial state or management of the farm. Overall, few of the farm characteristics we consider affect drought outcomes in systematic ways.

Our regressions indicate that larger farms in both sectors borrow more in droughts, and they may be (proportionally) less severely affected in terms of profits. For dairy farms, higher 
fertiliser intensity is associated with a larger reduction in profits when drought intensity rises, potentially suggesting lower drought resilience with increasing land-use intensity.

Characteristics associated with geographic location such as soil texture, slope, distance to nearest city and the share of dairy in the area do not seem to make a material difference to drought outcomes. Reflecting the spatial precision of reported farm locations, most of these variables are specified at the meshblock rather than the farm scale, and it is possible they are too coarsely measured to identify their effect on drought outcomes. It is also possible that their impact on droughts is indeed negligible.

Lack of strong evidence for the importance of the pre-drought financial state of the farm, as described by indicators for bank loans, net loss and negative equity, is more unexpected. Dairy farms with bank loans in the previous year are found to produce more gross output during a drought, but they do not appear to do any better in terms of profit. Moreover, previous losses and negative equity also do not affect drought outcomes in our results.

Surprisingly, potential irrigation does not significantly change any of our outcome variables: farms with a higher share of irrigated land do not seem to be at an advantage in overcoming droughts. This finding may be a result of the generally low quality of the irrigation data collected in Agricultural Production Surveys. Other studies using irrigation variables from the same dataset have reached similar conclusions (Fabling \& Morris, 2013; Pourzand et al., 2020).

Ultimately, our results only partially accomplish our original goals of identifying farm-level drought impacts and determinants of farm resilience. Most of the estimated marginal drought effects are significant, consistent across specifications and of the expected sign. Yet despite our access to a large integrated micro-dataset of farm businesses, the great care we have taken to construct and clean the sample, the exogeneity of weather outcomes and our use of fixedeffects panel methods, some of the estimates do not seamlessly fit the context of our data and other results. The lack of strong evidence for the role of various farm characteristics in shaping drought outcomes should, perhaps, not be greatly surprising. On the one hand, several of these variables represent aggregated information or are noisy for other reasons. On the other hand, plenty of anecdotal as well as research evidence exists to emphasize the role of farmers' personal characteristics in addition to (or, in some cases, rather than) farm characteristics in creating resilience (Cradock \& Mortimer, 2013; Cradock et al., 2019; Burton \& Peoples, 2008). Psychological, social and demographic attributes have, for example, been found to be more important in a dairy farm's resilience to droughts than differences in production levels (Cradock 
\& Mortimer, 2013). In this research, we were unable to test the importance of these factors as demographic information on farmers was not available 


\section{References}

Apatov, Eyal, Richard Fabling, Adam Jaffe, Michele Morris and Matt Thirkettle. 2015. “Agricultural Productivity in New Zealand: Estimating Production Functions Using the Longitudinal Business Database." Motu Working Paper 15-13. Wellington: Motu Economic and Public Policy Research. Bevin, Sean. 2007. "Economic Impact of the 2007 East Coast Drought on the Sheep and Beef Sector." Economic Solutions Ltd, Napier.

Burton Rob and Sue Peoples. 2008. "Learning from Past Adaptation to Extreme Climatic Events: A Case Study of Drought. Part A: Summary Report." MAF Policy - Climate Change.

Butcher Partners Ltd. 2009. "Regional and national impacts of the 2007-2009 drought." Report prepared for MAF Policy.

Clark, Anthony; A. Mullah, and A. Porteous. 2011. "Scenarios of Regional Drought under Climate Change." NIWA Client Report WLG2010-32. Wellington: Ministry of Primary Industries.

Cradock-Henry, Nicholas and Claire Mortimer. 2013. "Operationalising resilience in dairy agroecosystems." MPI discussion paper no 2013/LCR4761, Ministry for Primary Industries.

Cradock-Henry, Nicholas, Katherine McCusker and Stuart Ford. 2019. "Impacts, indicators and thresholds in sheep and beef land management systems." MPI Technical Paper No: 2019/07, Ministry for Primary Industries.

Fabling, Richard. 2011. “Keeping It Together: Tracking Firms on New Zealand's Longitudinal Business Database." Motu Working Paper 11-01. Wellington: Motu Economic and Public Policy Research. Fabling, Richard, and Lynda Sanderson. 2016. “A Rough Guide to New Zealand's Longitudinal Business Database (2nd Edition)." Motu Working Paper 16-03. Wellington: Motu Economic and Public Policy Research.

Fabling, Richard, and Michele Morris. 2013. "Agricultural Productivity and the Importance of Irrigation." Unpublished Motu Working Paper. Wellington: Motu Economic and Public Policy Research.

Grimes, Arthur and Andrew Aitken. 2008. "Water, water somewhere: the value of water in a drought-prone farming region." Motu Working Paper 08-18. Wellington: Motu Economic and Public Policy Research.

Kamber, Gunes, Chris McDonald, and Gael Price. 2013. "Drying out: Investigating the Economic Effects of Drought in New Zealand." Reserve Bank of New Zealand Analytical Note 2013/2. Wellington: Reserve Bank of New Zealand.

Lawes, R. and Kingwell, R. 2012. "A longitudinal examination of business performance indicators for drought-affected farms." Agricultural Systems 106, 94-101. 
Ministry of Agriculture and Forestry. 2009. "Pastoral Monitoring Report 2008." Wellington: Ministry of Agriculture and Forestry.

Ministry for the Environment. 2016. "Climate change projections for New Zealand: atmosphere projections based on simulations undertaken for the IPCC 5th assessment." Wellington: Ministry for the Environment.

Ministry for the Environment and Stats NZ. 2017. “New Zealand's Environmental Reporting Series: Our atmosphere and climate 2017." Wellington: Ministry for the Environment and Stats NZ.

NZIER. 2017. "Dairy trade's economic contribution to New Zealand." Report to DCANZ, February 2017.

OECD. 2016. "Mitigating Droughts and Floods in Agriculture: Policy Lessons and Approaches." OECD Studies on Water. OECD Publishing. http://dx.doi.org/10.1787/9789264246744-en.

Peck, D.E. and Adams, R.M. 2010. “Farm-level impacts of prolonged drought: is a multiyear event more than the sum of its parts?" Australian Journal of Agricultural and Resource Economics 54, $43-60$.

Porteous, Alan and Brett Mullan. 2013. "The 2012-13 drought: an assessment and historical perspective." MPI Technical Paper No: 2012/18, Prepared for the Ministry for Primary Industries by NIWA.

Pourzand, Farnaz, Ilan Noy and Yiğit Sağlam. 2020. "Droughts and farms' financial performance: a farm-level study in New Zealand." Australian Journal of Agricultural and Resource Economics, 59, $1-27$.

Seyb, Allyson. 2003. "The Longitudinal Business Frame." Wellington, New Zealand: Statistics New Zealand.

Statistics New Zealand. 2014. "New Zealand Business Demography Statistics: At February 2014." Yusuke Kuwayama, Alexandra Thompson, Richard Bernknopf, Benjamin Zaitchik and Peter Vail. 2019. "Estimating the Impact of Drought on Agriculture Using the U.S. Drought Monitor," American Journal of Agricultural Economics, 101:1, 193-210. 


\section{Appendix}

Table A1. Key sample restrictions and associated changes in sample size

\begin{tabular}{|c|c|c|c|}
\hline Sample restriction & Dairy & Sheep-beef & Combined \\
\hline $\begin{array}{l}\text { Returned valid IR10 and APS/APC forms, in } \\
\text { the same industry in both sources }\end{array}$ & - & - & 94,401 \\
\hline Had productive land & - & - & 94,047 \\
\hline $\begin{array}{l}\text { Livestock on farm is mostly cattle or sheep } \\
\text { (by head count) }\end{array}$ & - & - & 93,774 \\
\hline $\begin{array}{l}\text { More hectares of livestock farming than } \\
\text { forestry }\end{array}$ & - & - & 93,702 \\
\hline $\begin{array}{l}\text { Majority of dairy stock on land owned by } \\
\text { farm }\end{array}$ & 24,999 & 64,929 & 89,928 \\
\hline $\begin{array}{l}\text { At least } 80 \% \text { of weighted stock units are } \\
\text { dairy cattle or sheep and beef cattle }\end{array}$ & 22,497 & 61,344 & 83,841 \\
\hline $\begin{array}{l}\text { Successfully matched productivity and } \\
\text { financial data }\end{array}$ & 22,479 & 61,329 & 83,808 \\
\hline Successfully matched weather data & 22,449 & 61,236 & 83,685 \\
\hline Operates in single Regional Council & 21,672 & 59,961 & 81,633 \\
\hline $\begin{array}{l}\text { Regional Council does not change through } \\
\text { time }\end{array}$ & 21,288 & 58,638 & 79,926 \\
\hline Operates in a single meshblock & 17,844 & 52,725 & 70,569 \\
\hline Firm was active in the previous tax year & 17,415 & 51,249 & 68,664 \\
\hline No outliers in dependent variables & 17,046 & 50,199 & 67,245 \\
\hline
\end{tabular}



